\title{
DESEMPENHO DE DIFERENTES MEIOS DE CULTURA UTILIZADOS NA AVALIAÇÃO DE FUNGOS PRESENTES EM AMBIENTES DE PRODUÇÃO DE ALIMENTOS
}

\author{
MÁRCIO ADRIANI GAVA
}

Dissertação apresentada àEscola Superior Superior de Agricultura "Luiz de Queiroz", Universidade de São Paulo, para obtenção do título de Mestre em Ciências, Área de Concentração: Microbiologia Agrícola.

\author{
PIRACICABA \\ Estado de São Paulo - Brasil \\ Fevereiro - 2002
}




\title{
DESEMPENHO DE DIFERENTES MEIOS DE CULTURA UTILIZADOS NA AVALIAÇÃO DE FUNGOS PRESENTES EM AMBIENTES DE PRODUÇÃO DE ALIMENTOS
}

\author{
MÁRCIO ADRIANI GAVA \\ Biólogo
}

Orientador: Prof. Dr. CLÁUDIO ROSA GALLO

Dissertação apresentada àEscola Superior Superior de Agricultura "Luiz de Queiroz", Universidade de São Paulo, para obtenção do título de Mestre em Ciências, Área de Concentração: Microbiologia Agrícola.

PIRACICABA

Estado de São Paulo - Brasil

Fevereiro -2002 
Dados Internacionais de Catalogação na Publicação (CIP)

DIVISÃO DE BIBLIOTECA E DOCUMENTAÇÃO - ESALQ/USP

\section{Gava, Márcio Adriani}

Desempenho de diferentes meios de cultura utilizando na avaliação de fungos presentes em ambientes de produção de alimentos / Márcio

Adriani Gava. - - Piracicaba, 2002.

50 p. : il.

Dissertação (mestrado) - - Escola Superior de Agricultura Luiz de Queiroz, 2002.

Bibliografia.

1. Contaminação de alimento 2. Meio ambiente 3. Microbiologia de alimentos 4. Processamento de alimento I. Título

CDD 614.3

"Permitida a cópia total ou parcial deste documento, desde que citada a fonte - $\mathrm{O}$ autor" 


\section{AGRADECIMENTOS}

Ao Professor Dr. Cláudio Rosa Gallo pela orientação, apoio e ensinamentos;

À BIOAGRI LABORATÓRIOS LTDA pelo financiamento da pesquisa;

Aos Professores Dr. Luiz Eduardo Gutierrez, Dra Marília Oetterer e Dra Silene Bruder Sarmento pelas correções e sugestões;

À Engenheira Florestal Izabel Christina Gava de Souza pela colaboração nas análises estatísticas e sugestões;

À Dra. Márcia Regina de Camargo Ranzani pelo apoio laboratorial e sugestões;

À Camila Frutoso no auxílio laboratorial;

Ao Marcos Favarim no auxílio na coleta de amostras;

A todos que de uma forma ou de outra contribuíram na realização deste trabalho. 


\section{SUMÁRIO}

Página

LISTA DE QUADROS ………………………………............. iv

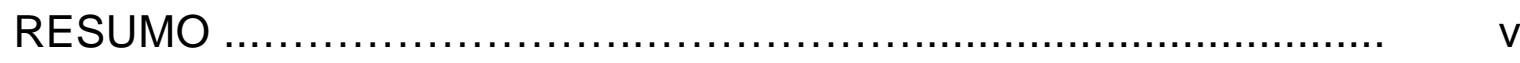

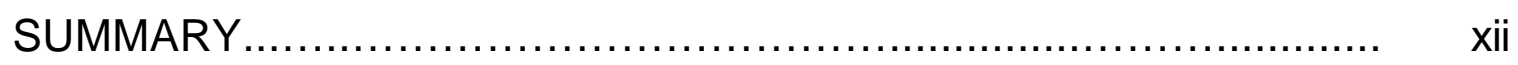

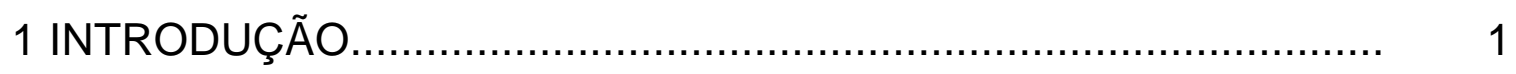

2 REVISÃO DE LITERATURA.....................................................

2.1 Qualidade microbiológica do ar em ambientes interiores............ 4

2.2 Métodos para avaliar a qualidade do ar.................................... 9

3 MATERIAL E MÉTODOS ..................................................... 11

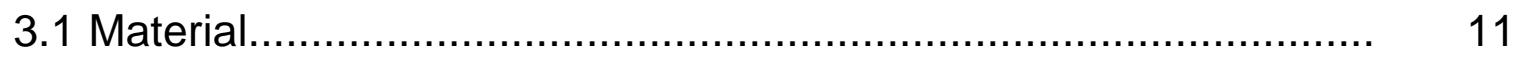

3.1.1 Amostrador microbiológico de ar.............................................. 11

3.1.2 Meios de Cultura .................................................................. 12

3.2 Métodos.......................................................................... 16

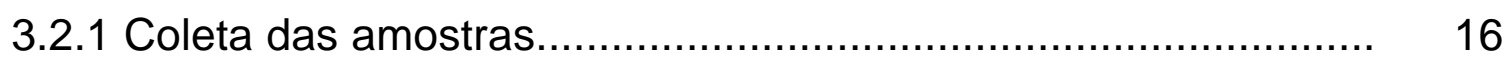

3.2.2 Incubação....................................................................... 17

3.2.3 Contagem de unidades formadoras de colônias de fungos

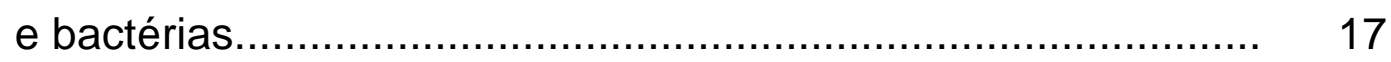

3.2.4 Avaliação estatística dos resultados de contagem...................... 18

3.2.5 Avaliação qualitativa dos resultados ........................................ 18

3.2.5.1 Identificação dos fungos presentes........................................ 18

3.2.5.2 Avaliação dos meios de cultivo e identificação dos fungos fungos patogênicos e toxigênicos e estudo de bactérias........ 
4 RESULTADOS E DISCUSSÃO............................................... 20

4.1 Avaliação quantitativa........................................................... 20

4.2 Avaliação qualitativa ....................................................... 27

4.3 Avaliação da contagem total de bactérias................................... 37

4.4 Avaliação ambiental das instalações amostradas....................... 38

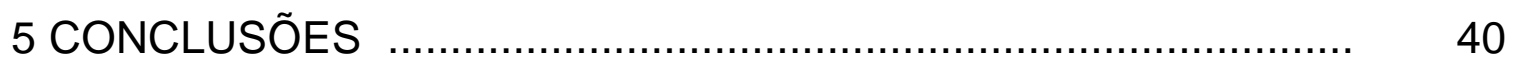

REFERÊNCIAS BIBLIOGRÁFICAS......................................... 42

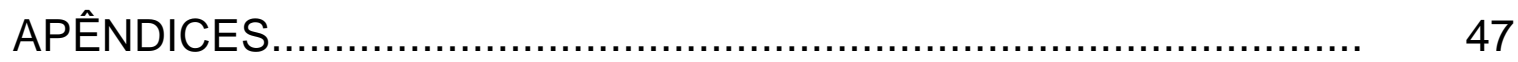




\section{LISTA DE QUADROS}

Página

1 Unidades formadoras de colônias $/ \mathrm{m}^{3}$ (valores médios) em diferentes meios de cultura, nos ambientes de produção de doce de leite e de amendoim

2 Unidades formadoras de colônias $/ \mathrm{m}^{3}$ (valores médios) em diferentes meios de cultura, nos ambientes de empacotamento e de produção de embutidos

3 Contagem em ufc $/ \mathrm{m}^{3}$, de fungos, em diferentes meios de cultura envolvendo todos os ambientes e épocas de coleta.

4 Unidades formadoras de colônias $/ \mathrm{m}^{3}$ (valores médios de cinco repetições) nos meios de cultura DRBC e Sabourand, nos ambientes de produção de doce de leite e de amendoim

5 Unidades formadoras de colônias $/ \mathrm{m}^{3}$ (valores médios de cinco repetições) nos meios de cultura DRBC e Sabourand, nos ambientes de empacotamento e de produção de embutidos. 
6 Gêneros de fungos desenvolvidos em diferentes meios de cultura no ambiente de produção de doce de leite

7 Gêneros de fungos desenvolvidos em diferentes meios de cultura no ambiente de produção de amendoim.

8 Gêneros de fungos desenvolvidos em diferentes meios de cultura no ambiente empacotamento de embutidos

9 Gêneros de fungos desenvolvidos em diferentes meios de cultura no ambiente de produção de embutidos.

10 Diâmetro e cor das colônias de Aspergillus parasiticus ao longo do período de incubação.

11 Diâmetro e cor das colônias de Aspergillus fumigatus ao longo do período de incubação.

12 Diâmetro e cor das colônia de Aspergillus niger ao longo do período de incubação.

13 Diâmetro e cor das colônias de Aspergillus flavus ao longo do período de incubação.

14 Diâmetro e cor das colônias de Fusarium verticulloides ao longo do período de incubação

15 Diâmetro e cor das colônias de Fusarium moniliforme ao longo do período de incubação 
16 Diâmetro e cor das colônias de Stachybotrys chartarum ao longo do período de incubação

17 Diâmetro e cor das colônias de Histoplasma capsulatum ao longo do período de incubação.

18 Unidades formadoras de colônias $/ \mathrm{m}^{3}$ (valores médios) de bactérias nos diferentes ambientes amostrados (médias

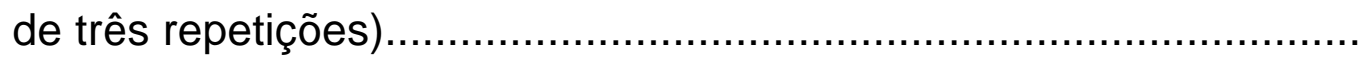

19 Correção estatística "Feller" 


\title{
DESEMPENHO DE DIFERENTES MEIOS DE CULTURA UTILIZADOS NA AVALIAÇÃO DE FUNGOS PRESENTES EM AMBIENTES DE PRODUÇÃO DE ALIMENTOS
}

\author{
Autor: MÁRCIO ADRIANI GAVA \\ Orientador: Prof.Dr.CLÁUDIO ROSA GALLO
}

\section{RESUMO}

O presente estudo foi dividido em duas fases; a primeira visou avaliar o desempenho de diversos meios de cultura, para fungos, no ar de ambientes de produção de alimentos, através da resposta de contagem e identificação dos gêneros que podem conter espécies indesejáveis; também foi avaliada a condição ambiental juntamente com a contagem total de bactérias. O ambiente de duas áreas foi utilizado para a pesquisa, uma indústria de doces, produção de doce de leite e doce de amendoim, na Cidade de Ribeirão Preto (SP) e, outra, uma indústria de embutidos, nos setores de empacotamento e produção, na Região de Piracicaba (SP). Os meios de cultura utilizados foram: "Dichloran Rose Bengal Chloramphenicol Ágar" (DRBC), "Sabouraud Dextrose a 4\% Ágar", "Malt Ágar" (MA), "Malt Extract Agar - Yeast and Molds" (MEAYM), "Plate Count Ágar-Cloranfenicol" (PCA-Cloranfenicol), "Dichloran 18\% Glycerol Ágar" (DG 18), Batata Dextrose Ágar (BDA) e "Oxytetracycline Glucose Yeast 
Agar" (OGY); para a contagem de bactérias foi utilizado o meio "Plate Count Agar" (PCA). Cada um dos pontos foi amostrado em triplicata utilizando um amostrador de impactação linear. A segunda fase do projeto avaliou os meios de cultura "Dichloran Rose Bengal Chloramphenicol Ágar" (DRBC), "Sabouraud Dextrose a 4\% Ágar" selecionados da primeira fase. Novas coletas foram realizadas amostrando cinco repetições em cada um dos pontos, que permaneceram os mesmos da primeira fase. Em paralelo foram utilizadas culturas puras de Aspergillus flavus, Aspergillus fumigatus, Aspergillus niger, Aspergillus parasiticus, Fusarium moniliforme, Fusarium verticulloides, Histoplasma capsulatum e Stachybotrys chartarum, inoculando os dois meios selecionados e avaliando o desenvolvimento desses fungos ao longo do período de incubação de sete dias, a $28^{\circ} \mathrm{C}$, para servir de parâmetro de comparação com as coletas de ar realizadas no mesmo período, a fim de se verificar se algum desses fungos indesejáveis estaria presente nas amostras de ar. De acordo com os resultados obtidos, os meios DRBC e Sabouraud Dextrose a 4\% Ágar, foram, estatisticamente, melhores que os demais meios testados, apresentando um maior número de unidades formadoras de colônias $/ \mathrm{m}^{3}$. O meio de Extrato de Malte diferenciou estatisticamente dos demais e teve o menor desempenho para a quantificação desses microrganismos no ar. A recomendação do melhor meio para identificação de fungos no ar de indústrias alimentícias não foi conclusiva, com exceção do PCACloranfenicol que apresentou baixa diversidade de gêneros, sendo considerado reprovado. No geral foi observado um número elevado de unidades formadoras de colônias de fungos e bactérias $/ \mathrm{m}^{3}$ durante as amostragens. A avaliação quali-quantitativa dos ambientes estudados sugere que esses não se encontram em condições adequadas, sendo necessária a elaboração de um padrão referencial para o monitoramento da indústria alimentícia em nosso país. O amostrador utilizado nas coletas 
promoveu rapidez nas coletas e proporcionou a expressão dos resultados em medidas confiáveis, por ser um equipamento que permite calibração em seu sistema de aspiração de ar. 


\title{
PERFORMANCE OF DIFFERENT CULTURE MEDIA USED IN THE EVALUATION OF FUNGI FOUND IN FOOD PRODUCTION ENVIRONMENTS
}

\author{
Author: MÁRCIO ADRIANI GAVA \\ Adviser: Prof.Dr.CLÁUDIO ROSA GALLO
}

\section{SUMMARY}

The present study consisted of two phases. The first one aimed at evaluating the performance of different culture media for fungi found in the air of food production environments, through the results of counting and identifying genders that may contain undesirable species. The environmental condition was also evaluated along with a total bacteria counting. The present work took place in two different places, an industry which produces sweets made from milk or peanuts, in Ribeirao Preto city (SP) and, in the packing and production sections of a meat encased products industry located in Piracicaba region (SP). The culture media used were: "Dichloran Rose Bengal Chloramphenicol Agar (DRBC)", "Sabouraud Dextrose 4\% Agar (MA)", "Malt Extract Agar Yeast and Molds (MEAYM)", "Plate Count Agar - Chloramphenicol (PCAChloramphenicol)", "Dichloran 18\% Glycerol Agar (DG 18)", "Potato Dextrose Agar (BDA)" and 
"Oxytetracycline Glucose Yeast Agar (OGY)". The medium used for the bacteria counting was "Plate Count Agar (PCA)". Three replicates of each sampled spot were obtained by using a linear impacting sampler. The second phase of this project evaluated the following culture media, selected during the first phase of this study: "Dichloran Rose Bengal Chloramphenicol Agar (DRBC)" and "Sabouraud Dextrose 4\% Agar". New sample collections (five replicates) were carried out for each of the spots selected. The sampled spots were the same for both phases. In a parallel manner, pure cultures of Aspergillus flavus, Aspergillus fumigatus, Aspergillus niger, Aspergillus parasiticus, Fusarium moniliforme, Fusarium verticulloides, Histoplasma capsulatum and Stachybotrys chartarum were employed to inoculate the two selected media. The development of these fungi was evaluated throughout a 7-day-incubation period, at $28^{\circ} \mathrm{C}$, to function as a comparative reference for the air samples obtained in the same period in order to verify if any of these undesirable fungi was present in the air samples. According to the results obtained, DRBC and Sabouraud Dextrose 4\% Agar media were statistically superior than the others, presenting a higher number of colony forming units $/ \mathrm{m}^{3}$. The Malt Extract medium was statistically different from the others and showed the worse performance as to the quantification of microorganisms present in the air. There was no conclusive recommendation as to the best medium for the identification of fungi found in the air of food industries, except for PCA-Chloramphenicol, which showed low diversity of genders and was discarded. In general, a high number of fungi and bacteria colony forming units $/ \mathrm{m}^{3}$ was observed during the sampling procedures. The qualitative-quantitative evaluation of the environments studied suggests that they do not present adequate conditions, evidencing the need for the establishment of a referential standard in order to monitor food industries in our country. The sampler used in this work allowed a quick sample 
collection and a reliable expression of results, as this equipment enables the calibration of its air intake system. 


\section{INTRODUÇÃO}

A contaminação microbiológica do ar tem sido pouco enfatizada na comunidade científica brasileira. O falecimento do Sr. Ministro Sérgio Motta, em abril de 1998, despertou discussão sobre o assunto, uma vez que se suspeitou de infecção generalizada induzida por microrganismos de risco à saúde, presentes no ar de seu gabinete.

Considerando a preocupação mundial com a qualidade do ar de ambientes climatizados e a ampla e crescente utilização de sistemas de ar condicionado no país, em função das condições climáticas, o Ministério da Saúde propõe, através da portaria n $n^{0} 3.523 / G M$ de 28 de agosto de 1998, que sejam determinados padrões de qualidade do ar em ambientes climatizados, bem como, o seu monitoramento.

Recentemente, a Resolução RE $n^{0} 176$ de 24 de outubro de 2000, estabeleceu critérios para monitoramento sobre a qualidade do ar interior em ambientes climatizados artificialmente, definindo a identificação das fontes poluentes de natureza biológica, química e física, e métodos analíticos, além de recomendações para controle. Para padrões biológicos é estabelecido um limite máximo de 750 unidades formadoras de colônias por $\mathrm{m}^{3}\left(\mathrm{ufc} / \mathrm{m}^{3}\right)$ para fungos, desde que não ocorram espécies patogênicas e toxigênicas. Para coleta foi adotado um amostrador de ar de impactação com acelerador linear, e indicado os seguintes meios de cultivo: Ágar Extrato de Malte, Ágar Sabouraud Dextrose a 4\%, Ágar Batata Dextrose ou outro, desde que cientificamente validado. 
Observa-se que em termos de meios de cultura indicados a resolução é inconsistente, pelo fato de não haver uma especificação de um meio padrão, o que poderia ocasionar interpretações distintas das condições de um mesmo ambiente. Estudos quanto à comparação dos meios de cultura recomendados para contagem e identificação de fungos citados acima e outros meios de importância tornam-se necessários.

A World Health Organization (1988) discutindo sobre a qualidade do ar de ambiente interno, relata que a contaminação microbiológica, em ambientes interiores de edifícios, é tida como responsável substancial nas faltas ao trabalho. Relata, ainda, que na população em geral, verifica-se uma média normal de 5 a 10 dias/ano de restrição de atividade per capita, devida à infecções agudas e episódios alérgicos, os quais poderiam ser reduzidos, significativamente, com o controle dos contaminantes. Alguns fatores referentes à arquitetura das edificações, como lotação e recirculação de ar podem, também, promover a dissiminação de patógenos pelo ar, quando emitidos pelos ocupantes que sofrem de tuberculose, sarampo, varicela e outras doenças.

Componentes dos sistemas de ventilação como torres de refrigeração, aparelhos de ar condicionado, umidificadores e desumidificadores podem promover o crescimento de fungos, bactérias e outros microrganismos. Estes microrganismos podem atingir patamares elevados de crescimento quando o ambiente proporciona condições de umidade e temperatura ideais. Além de reações de irritações e alergias aos ocupantes, nos casos de ambientes de manipulação de alimentos, podem interferir na qualidade do produto final.

A preocupação com a sanidade dos alimentos tem sido cada vez mais colocada em destaque. A manipulação de alimentos em ambientes sem controle dos contaminantes pode se tornar potencial de risco, devido à contaminação propagar-se através dos produtos. 
Baseado em especificações de monitoramento de áreas comuns, esta pesquisa visa contribuir para 0 controle de contaminantes microbiológicos do ar na área alimentícia.

Os objetivos desta pesquisa foram:

a) aferir o desempenho de diversos meios de cultura para o crescimento de fungos, em relação à resposta de contagem e identificação dos gêneros que podem conter espécies indesejáveis, incluindo os meios recomendados pela Resolução do Ministério da Saúde;

b) expressar dentro de um campo amostral, as condições ambientais onde ocorre a manipulação de alimentos nas indústrias, tendo como produtosbase derivados do leite, do amendoim e embutidos cárneos da indústria frigorífica. 


\section{REVISÃO DE LITERATURA}

\subsection{Qualidade microbiológica do ar em ambientes interiores}

Os efeitos na saúde associados aos microrganismos presentes nos ambientes interiores têm mostrado a necessidade de monitoramento do ar de interiores e motivado as pesquisas de métodos de detecção e identificação de microrganismos.

Lacaz (1970) cita que, em 1924, Van Leewen estudou as relações clínicas entre asma e clima na Holanda, atribuindo grande importância etiológica aos esporos de fungos e bactérias do ar como agentes extrínsecos causadores da chamada "asma climática". O autor revisando sobre os contaminantes biológicos do ar verificou que numerosos fungos na poeira e no ar desempenham papel importante como elementos alergizantes. De acordo com Feldman (1995), um programa de monitoramento para contaminantes do ar como poeira, esporos de Aspergillus fumigatus e endotoxinas pode ser um instrumento valioso na saúde pública e ambiental.

Segundo Pelczar et al. (1981) o grau de contaminação do ar interno é influenciado por fatores, tais como as taxas de ventilação, o número de pessoas que ocupam o ambiente, a natureza e o grau de atividade exercida por esses indivíduos.

Como componentes biológicos do ar em ambientes internos, aclimatados artificialmente, Kulcsar Neto \& Siqueira (1998) citam os microrganismos como cohabitantes, apresentando-se em curva 
exponencial de crescimento. Os autores mostram que há prevalência de bactérias, como: Legionella pneumophila, Bacillus sp, Flavobacterium sp, Pseudomonas aeruginosa, Staphylococcus aureus, Mycobacterium tuberculosis, Neisseria meningitidis, Streptococcus pneumoniae e Actinomyces thermophilia, e de fungos, como: Paracoccidioides brasiliensis, Histoplasma capsulatum, Cephalosporium sp, Aspergillus sp, Penicillium sp, Cladosporium sp e Fusarium sp.

Segundo Brickus \& Aquino Neto (1999) a baixa qualidade do ar de interiores tem sido relacionada com efeitos adversos à saúde humana, levando a Organização Mundial de Saúde (OMS) a classificar a Síndrome do Edifício Doente (SED) como um problema de saúde pública. Os sintomas decorrentes da síndrome podem estar ligados a poluentes de origem química ou biológica, sendo eles: irritação e obstrução nasal, desidratação e irritação da pele, irritação e secura na garganta, irritação e sensação de secura nas membranas dos olhos, dor de cabeça, letargia e cansaço generalizado, levando àperda de concentração.

Kulcsar Neto \& Siqueira (1998) citam que os padrões referenciais para analisar os resultados de qualidade microbiológica do ar de interiores são classificados em relativos, qualitativos, quantitativos, qualitativos/quantitativos e ocupacionais. Com base nesta extensa revisão e considerando a necessidade de serem implantados procedimentos que visem minimizar o risco potencial à saúde dos ocupantes, que têm permanência prolongada nestes ambientes, os autores recomendam a adoção de parâmetros qualitativos e quantitativos que permitam uma interpretação científica sobre a qualidade do ar de ambientes interiores e a correta tomada de decisão quanto à intervenção, mais especificamente, com relação a sistemas de ar condicionado, ventilação e aquecimento.

Segundo Padrão Referencial Brasileiro Microbiológico (1998), o Conselho Científico da Brasindoor (Sociedade Brasileira de Meio Ambiente 
e de Qualidade do Ar de Interiores) aprovou, em 1998, o seguinte referencial brasileiro para ambientes:

a) Qualitativo: não são admitidos nos ambientes interiores:

-Fungos - Histoplasma capsulatum, Cryptococcus neoformans, Paracoccidioides brasiliensis, Aspergillus parasiticus, A. flavus, $A$. fumigatus, Stachybotrys atra e Fusarium moniliforme.

-Bactérias - Legionella pneumophila

b)Quantitativo: Valor Máximo Aceitável $=750 u f c / \mathrm{m}^{3}$ de ar.

c)Relativo: Classificação dos ambientes dentro dos valores máximos aceitáveis. $O$ valor máximo relativo é dado pela seguinte expressão:

$\operatorname{Ar}$ ambiental Interior(I) = Ar ambiental Exterior(E).1,5; então os ambientes são classificados em: a) Ambientes em boas condições $I / E<1,5$; b) Ambientes em regulares condições $\mathrm{I} / \mathrm{E}=1,5-2,0$; e c) Ambiente em más condições I/E > 2,0.

Ezeonu et al.(1994) colonizaram com fungo, em laboratório, materiais de isolação acústica e fibra de vidro térmica usados no aquecimento, ventilação e sistemas de ar condicionados. A mistura de fungos, principalmente Aspergillus versicolor, Acremonium obclavatum e Cladosporium herbarum produziu odores voláteis, incluindo 2-etil hexanol, ciclohexano, e benzeno. Segundo o autor, o benzeno é classificado como um composto químico perigoso pela "Environmental Protection Agency e "Occupational Safety and Health Administration", o ciclohexano e 2-etil hexanol são conhecidos como irritantes dos olhos e da pele. Este estudo demonstrou que fungos nos sistemas de aquecimento, ventilação e ar condicionado podem desempenhar um papel significativo nos problemas de saúde nos ocupantes de edifícios com essas características.

Macneil et al.(1995) revisam métodos moleculares na detecção de fungos e bactérias comuns no ar de interiores. Segundo os autores as técnicas moleculares para detecção e identificação de bactérias estão 
desenvolvidas e disponíveis para uma variedade de espécies. Para a detecção e identificação de fungos tem sido tratada com limites, pois vários gêneros comuns no ar de interiores não são detectados por essas técnicas.

Angulo-Romero et al.(1996) estudaram a presença de fungos no ar interno de doze escolas na Espanha durante dois anos. Foram coletadas 456 amostras usando um aspirador de pó e analisadas para cultura de fungos. Das colônias isoladas $38 \%$ pertenciam a patogênicos capazes de causar infecções ou doenças de hipersensibilidade. Dos 91 gêneros identificados, os mais freqüentes foram Alternaria, Aspergillus e várias espécies de Penicillium. Os autores observaram também que a maioria destes fungos apresentou variações sazonais na concentração, a qual foi mais abundante entre os meses de abril e outubro.

Poucos estudos sobre o monitoramento microbiológico do ambiente de indústrias alimentícias têm sido observados na literatura.

Ligugnana e Fung (1990) desenvolveram um programa de amostragem para mostrar o impacto das atividades dos trabalhadores e da higiene do local na qualidade microbiana do ar e superfícies no ambiente de trabalho na indústria de alimentos. Foram utilizados o amostrador de ar "SAS" e o método Agar contact plate. Foram avaliados: o efeito da limpeza das mãos e utensílios na carga microbiológica nas superfícies de trabalho, efeito de desinfetantes aerossóis nos microrganismos transportados pelo ar nos ambientes fechados, efeito da fumigação na redução de fungos, nível de higiene do ar em ambientes críticos como enchimento estéril e empacotamento de yogurt, detecção de microrganismos específicos pelo meio seletivo, e efeito da variação da umidade relativa na qualidade microbiana do ar. Os autores observaram que, para obter melhores resultados é importante que os empregados tenham boa vontade $\mathrm{e}$ entendam as razões dos procedimentos específicos de higiene. 
Sveum et al (1992) citam que o ar ambiente em áreas de empacotamento de alimentos é tido como um ponto crítico de controle.

Kurata (1994) cita que a qualidade do ar em áreas de empacotamento é um fator crítico no processamento de alimentos deterioráveis e, portanto, métodos de monitoramento do ar deverão ser estabelecidos com limites apropriados de níveis viáveis de microrganismos. O autor apresenta um plano de monitoramento de microrganismos transportados pelo ar em ambientes interiores de empacotamento na indústria alimentícia. Os amostradores do ar são "Brotest RCS" e o "RCS Plus", e os meios de cultura agar HS (rose bengal agar) e DG18 (dichloran 18\% glycerol). O autor propõe a seguinte classificação para a qualidade do ar em áreas de processamento e empacotamento de alimentos de acordo com o número de unidades formadoras de colônias de fungos $\left(\mathrm{ufc} / \mathrm{m}^{3}\right)$ :

Categoria $\mathrm{ufc} / \mathrm{m}^{3}$

I - condição microbiológica limpa

$0-10$

II - condição microbiológica sub-limpa $11-50$

III - condição normal do ambiente interior $51-100$ IV - condição ruim do ambiente interior $>100$

Padrões brasileiros para qualidade microbiológica do ambiente de indústrias alimentícias não existem em legislação. O trabalho de Kurata (1994) define padrões que podem servir de base para elaboração de padrões nacionais, entretanto, devemos considerar nossas condições ambientais tropicais, o que torna estudos em nossas condições ambientais indispensáveis. 


\subsection{Métodos para avaliar a qualidade do ar}

Segundo Flannigan \& Miller (1994), muitos trabalhos têm sido publicados sobre a presença de fungos no ar de interiores e relatam o número de "unidades formadores de colônias" (cfu/ $\mathrm{m}^{3}$ de $\mathrm{ar}$ ), alguns relatam sobre gêneros e poucos sobre a identificação de espécies, especialmente de gêneros mais complexos como Aspergillus, Fusarium e Penicillium. Os autores ressaltam que atenção insuficiente tem sido dada com relação ao desempenho do amostrador, tempo de permanência dos esporos no ar entre as coletas, meio de cultura utilizado e a identificação dos fungos.

Os microrganismos viáveis do ar podem ser determinados por uma série de métodos como: sedimentação, impactação em superfícies sólidas, filtração, centrifugação e precipitação eletrostática (Pelczar et al., 1981; Sveum et al., 1992). Dentre estes, os mais utilizados são os de sedimentação e impactação em superfícies sólidas. Os métodos de sedimentação possuem várias desvantagens, incluindo a quantificação de microrganismos no ar, ou seja, o número de partículas viáveis $/ \mathrm{m}^{3}$ de $\mathrm{ar}$, com baixa correlação, quando comparada com outros métodos quantitativos. Já o método de impactação, permite que sejam coletados volumes conhecidos de amostras, possibilitando a quantificação por $\mathrm{m}^{3}$.

A World Health Organization (1988), no que se refere àqualidade do ar de ambiente interno, ressalta que os métodos de amostragem para pólen, bactérias específicas e vírus estão próximos da padronização, o que não ocorre para fungos, micotoxinas e outros materiais biológicos. Este fato permanece nos dias atuais.

Pitt \& Hocking (1997) citam que o método mais simples para amostragem do ar é o da sedimentação. Entretanto, os autores ressaltam que a amostragem volumétrica do ar, através de um equipamento de impactação, é um indicador mais confiável da qualidade do ar. 
Visando estabelecer padronização na amostragem de microrganismos transportados pelo ar, Buttner \& Stetzenbach (1993), conduziram um experimento em laboratório para determinar a recuperação desses microrganismos utilizando um marcador biológico como controle. Quantidades conhecidas de esporos de Penicillium chrysogenum foram produzidas e inoculadas em uma área fechada, seguido de coletas com diferentes equipamentos impactadores, como: "Andersen six -stage", "Surface Air System", "Burkart" e "Depositional". Os amostradores "Andersen" e "Burkard" recuperaram o mais alto número de esporos comparados com a medida padrão de $P$. chrysogenum.

A importância do método de amostragem, seja para buscar padrões ambientais ou selecionar meios de cultivo, é que o mesmo permita reduzir ao mínimo as variáveis da coleta, como: volume amostrado e tempo de coleta. Dentre os métodos mais utilizados o de impactação proporciona coletas pontuais e rápidas com volumes definidos, elevando a confiança dos dados obtidos. 


\section{MATERIAL E MÉTODOS}

\subsection{Material}

\subsubsection{Amostrador microbiológico de ar}

Empregou-se um amostrador microbiológico de ar da marca MERCK denominado MAS-100 (Figura 1), um instrumento do tipo impactador, que aspira 0 ar através de uma placa perfurada. $O$ ar aspirado, que contém as partículas presentes no ar ambiente, atinge diretamente a superfície de uma placa de Petri de $90 \mathrm{~mm}$, que após o ciclo de coleta ter-se completado é incubada e as colônias são contadas e expressas como unidades formadoras de colônias ( $\mathrm{ufc} / \mathrm{m}^{3}$ ).

Características do equipamento: taxa nominal do fluxo de ar $=100 \mathrm{~L} / \mathrm{min} \pm$ 2,5\%; níveis de volumes de amostras de ar pré-definidos: 10, 20, 50, 100, 200, 250, 500, 750 e 1000 litros; níveis de volumes de amostras de ar usados nas coletas: variaram de 100 a $500 \mathrm{~L}$, sendo que a maioria das coletas foi efetuada em 250L. A escolha esteve em função da contaminação esperada nos ambientes estudados. De qualquer forma, as coletas por amostrador de ar tipo impactador não devem exceder 10 minutos sob pena de secagem do meio de cultura. $O$ equipamento compensa para os fatores que podem interferir no fluxo de ar escolhido tais como, o volume de ágar na placa de Petri ou variação no diâmetro da mesma. 


\subsubsection{Meios de Cultura}

Os meios de cultura foram elaborados conforme especificado a seguir:

A) "Dichloran Rose Bengal Chloramphenicol Agar" (DRBC) (Food and drug administration, 1998; Pitt \& Hocking, 1997)

Glicose. $10,0 \mathrm{~g}$

Peptona Bacteriológica..........................................................5,0 g

Fosfato de Potássio, monobásico...............................................1,0 g

Sulfato de Magnésio, heptahidratado.......................................... $0,5 \mathrm{~g}$

Rosa bengala (solução 5\%., p/v) ........................................... $0,5 \mathrm{~mL}$

Dicloran (2,6-dicloro-4-nitroanilina) (solução 0,2\%,p/v, em etanol)....1,0 mL

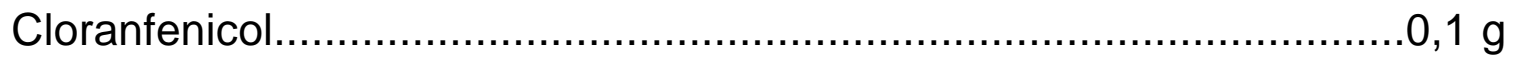

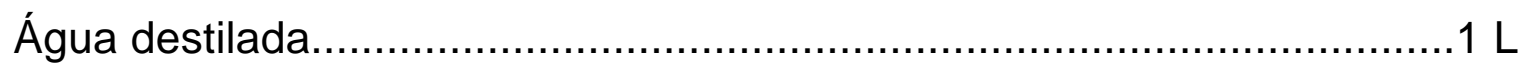

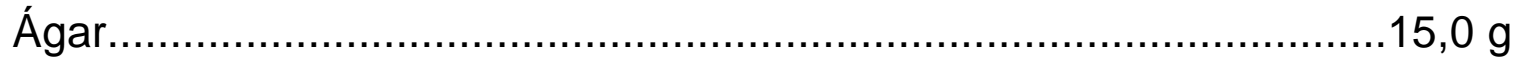

$\mathrm{pH}$ final 5,6

Os ingredientes foram misturados, o meio foi aquecido até dissolução do ágar, completando o volume para $1000 \mathrm{~mL}$ e esterilizado em autoclave a $121^{\circ} \mathrm{C}$ por 15 minutos; esfriado em banho maria a $50^{\circ} \mathrm{C}$ e distribuído em placa (15 a $20 \mathrm{~mL}$ por placa) sob condições assépticas.

O DRBC é um meio especialmente indicado para analisar amostras contendo fungos que se espalham como Mucor e Rhyzopus, pois, o dichloran e a rosa bengala, efetivamente, diminuem o crescimento dos fungos de crescimento rápido e, propiciam a detecção de outros propágulos de fungos e leveduras, que têm menor taxa de crescimento. 
B) "Dichloran 18\% Glycerol Agar" (DG18) (Food and drug administration, 1998; Pitt \& Hocking, 1997)

Glicerol. $220,0 \mathrm{~g}$

Glicose. $10,0 \mathrm{~g}$

Peptona. $5,0 \mathrm{~g}$

Fosfato de potássio monobásico. $1,0 \mathrm{~g}$

Sulfato de magnésio heptahidratado $.0,5 \mathrm{~g}$

Dicloran $(0,2 \%, \mathrm{p} / \mathrm{v}$, em etanol) $1,0 \mathrm{~mL}$ Ágar $15,0 \mathrm{~g}$

Cloranfenicol $0,1 \mathrm{~g}$

Água destilada. $1 \mathrm{~L}$

$\mathrm{pH}$ final 5,6

Os ingredientes acima foram misturados e fervidos até dissolução do ágar, e em seguida o volume acertado para $1000 \mathrm{~mL}$ com água destilada. Adicionou-se $220 \mathrm{~g}$ de glicerol e o meio foi esterilizado a $121^{\circ} \mathrm{C}$ por $15 \mathrm{~min}$. Foi submetido a resfriamento a $50^{\circ} \mathrm{C}$ e distribuído em placas de Petri sob condições assépticas. A baixa atividade de água desse meio reduz interferência de bactérias e fungos de crescimento rápido.

C) "Plate Count Agar" (PCA) (Food and drug administration, 1998; Pitt \& Hocking, 1997)

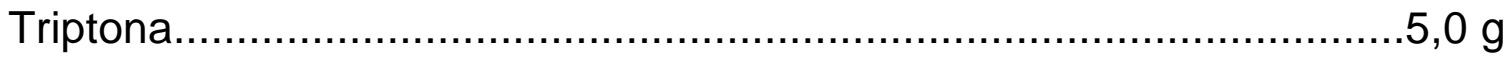

Extrato de levedura............................................................... $2,5 \mathrm{~g}$

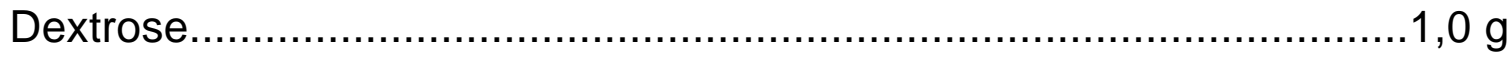

Ágar. $15,0 \mathrm{~g}$

Água destilada

$\mathrm{pH}$ final $7,0 \pm 0,2$

Os ingredientes foram dissolvidos e o meio aquecido até dissolução do ágar, resfriado e adicionado de $100 \mathrm{mg}$ de cloranfenicol por 
litro, para detecção de fungos e leveduras, e, sem antibiótico para contagem de bactérias mesófilas aeróbias. Em seguida foi autoclavado a $121^{\circ} \mathrm{C}$ por 15 minutos, resfriado a $50^{\circ} \mathrm{C}$ e distribuído em placas de Petri sob condições assépticas.

D) "Malt Agar" (MA) (Food and drug administration, 1998; Pitt \& Hocking, 1997)

Extrato de malte, em pó $20,0 \mathrm{~g}$ Ágar $20,0 \mathrm{~g}$ Água destilada. $.1 \mathrm{~L}$

Os ingredientes foram misturados, fervidos para dissolução do ágar e o meio foi esterilizado a $121^{\circ} \mathrm{C}$ por 15 minutos. Em seguida foi esfriado a $50^{\circ} \mathrm{C}$ e distribuído em placas de Petri sob condições assépticas.

E) "Malt Extract Agar - Yeast and Molds" (MEAYM) (Food and drug administration, 1998; Pitt \& Hocking, 1997)

Extrato de malte, em pó................................................................20,0 g

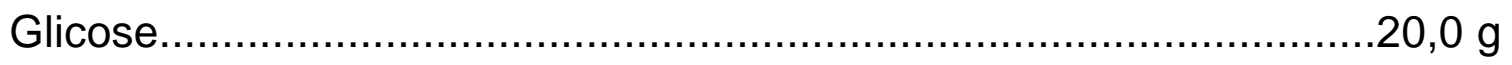

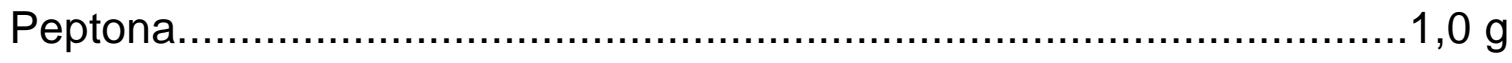

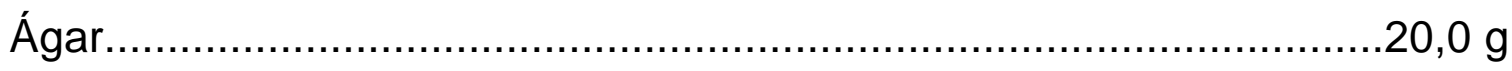

Água destilada.

$\mathrm{pH}$ final 5,4

Os ingredientes foram misturados, fervidos para dissolução do ágar e o meio foi esterilizado a $121^{\circ} \mathrm{C}$ por 15 minutos. Em seguida foi resfriado a $50^{\circ} \mathrm{C}$ e distribuído em placas de Petri sob condições assépticas. (Esse meio é recomendado para Aspergillus e Penicillium). 
F) "Batata Dextrose Agar" (BDA) (Food and drug administration, 1998; Pitt \& Hocking, 1997)

Infusão de batata.................................................................... $\mathrm{g}$

Dextrose ........................................................................................ $\mathrm{g}$

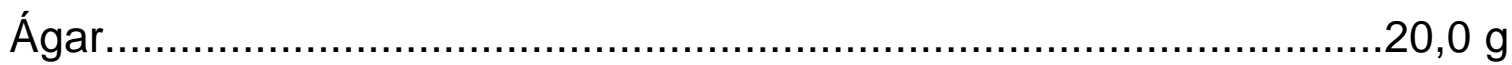

Água destilada.........................................................................

$\mathrm{pH}$ final $4,0-4,5 \pm 0,2$

O meio foi preparado e esterilizado conforme indicação do fabricante. Após esterilização foi adicionado cerca de $1 \mathrm{~mL}$ de solução de ácido tartárico a $10 \%$, para cada $100 \mathrm{~mL}$ de meio, a fim de se obter $\mathrm{pH}$ 4,0-4,5.

G) "Sabouraud Dextrose a 4\% Agar" (Food and drug administration, 1998) Polipeptona ou neopeptona.......................................................10,0 g

Dextrose.............................................................................. 40,0

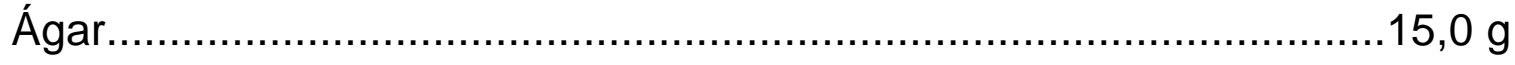

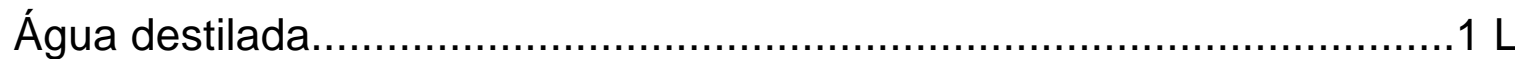

$\mathrm{pH}$ final 5,6 \pm 0,2

Meio normalmente indicado no cultivo e identificação de fungos patogênicos (Lacaz et al., 1998).

H) "Oxytetracycline Glucose Yeast Agar" (OGY) (Pitt \& Hocking, 1997)

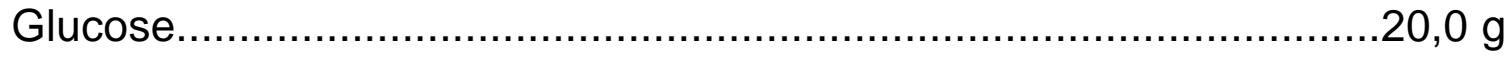

Extrato de Levedura.............................................................. $5,0 \mathrm{~g}$

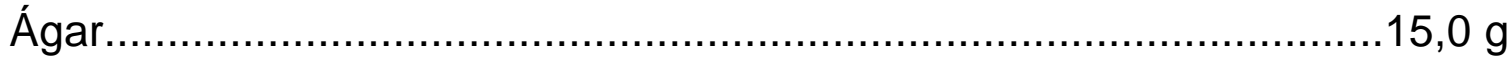

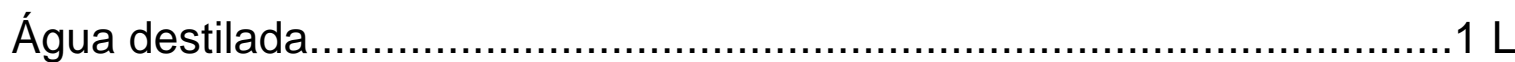

Os ingredientes foram misturados, fervidos para dissolução do ágar e o meio foi esterilizado a $121^{\circ} \mathrm{C}$ por 15 minutos. Esfriado a $50^{\circ} \mathrm{C}$, foi adicionado de $10 \mathrm{~mL}$ de oxitetraciclina esterilizada por filtração e, em seguida distribuído em placas de Petri sob condições assépticas. 


\subsection{Métodos}

A metodologia descrita está distribuída em duas fases de execução. A primeira fase propôs avaliar o desempenho dos meios de cultura, através de parâmetros utilizados para a escolha de um meio potencialmente melhor, a ser utilizado na enumeração total e a presença de interferentes (fungos de crescimento rápido).

Também foi avaliada a presença de bactérias totais mesófilas aeróbias, em Plate Count Agar (PCA), visando conhecer as condições do ambiente em relação a esse grupo de microrganismos e, ainda, fornecer dados para uma possível relação com o desenvolvimento de fungos nos meios estudados.

A segunda fase foi realizada utilizando os dois meios estatisticamente eleitos como os melhores. Em paralelo foi avaliado nesses meios 0 crescimento de algumas espécies patogênicas e toxigênicas durante a fase de incubação estipulada de cinco a sete dias.

De acordo com Padrão Referencial Brasileiro Microbiológico (1998), entre os fungos patogênicos não admitidos nos ambientes estão: Histoplasma capsulatum, Cryptococcus neoformans e Paracoccidiodes brasiliensis. Entre os fungos toxigênicos não admitidos nos ambientes estão: Aspergillus fumigatus, A. parasiticus, A. flavus, Stachybotrys atra e Fusarium moniliforme.

\subsubsection{Coleta das Amostras}

A amostragem foi realizada em dois locais distintos de processamento de alimentos, a saber: indústria de doces (produção de doce de leite e de doce de amendoim) e frigorífico (empacotamento e produção de embutidos cárneos). Na primeira fase foram realizadas 
coletas periódicas em diferentes épocas: indústria de doces entre maio de 2000 e janeiro de 2001; frigorífico entre setembro de 2000 e janeiro de 2001. Coletou-se de cada ambiente três placas para cada meio de cultura mencionado no item 3.1.2. Já na segunda fase foram realizadas coletas entre junho e julho de 2001 nos mesmos locais da primeira fase, porém utilizando-se somente os dois meios selecionados, Sabouraud e DRBC, coletando-se cinco placas para cada meio de cultura em cada um dos pontos amostrados.

\subsubsection{Incubação}

Após as coletas, as placas foram incubadas em estufa tipo BOD. Para a contagem total de fungos e a avaliação do crescimento de espécies toxigênicas e patogênicas empregou-se a temperatura de $28 \pm 1^{\circ} \mathrm{C}$ por cinco a sete dias; na contagem total de bactérias mesófilas a temperatura de $36 \pm 1^{\circ} \mathrm{C}$ por $24-48$ horas.

\subsubsection{Contagem de unidades formadoras de colônias de fungos e bactérias}

O número de unidades formadoras de colônias foi contado em cada placa e o resultado foi corrigido com a ajuda de uma tabela de correção estatística "Feller" (Quadro 19) e, em seguida calculou-se o número de ufc $/ \mathrm{m}^{3}$.

O método de correção estatística baseia-se no seguinte princípio: quanto maior a quantidade de microrganismos em cada amostragem, maior a probabilidade de que vários microrganismos entrem pelo mesmo orifício da placa perfurada. Foi utilizada uma tabela de conversão para cálculo, aplicando-se a fórmula Feller citado por MERCK (s.d.). 


\subsubsection{Avaliação estatística dos resultados de contagem}

Os dados de $u f c / \mathrm{m}^{3}$ (unidades formadoras de colônias por $\mathrm{m}^{3}$ ) foram submetidos a teste diagnóstico, visando verificar a homogeneidade de variância, segundo Nogueira (1991). Diante dos resultados obtidos nesta análise, os dados foram transformados em $\sqrt{u f c / m^{3}}$. A análise da variância foi realizada no esquema do delineamento inteiramente casualizado, por ambiente avaliado, e considerando todos os ambientes, segundo o modelo matemático:

$$
\begin{aligned}
& Y_{i j}=u+t_{i}+e_{i j}, \text { sendo: } \\
& Y_{i j}=\text { é o valor observado no i-ésimo meio de cultura da j-ésima }
\end{aligned}
$$
repetição;

$$
\begin{aligned}
& \mathrm{u}=\text { é a média geral dos valores observados; } \\
& \mathrm{t}_{\mathrm{i}}=\text { é o efeito do i-ésimo tratamento; } \\
& \mathrm{e}_{\mathrm{ij}}=\text { erro aleatório atribuído àobservação } Y_{\mathrm{ij}}
\end{aligned}
$$

Detectada a significância do Teste $F$, as médias dos tratamentos foram comparadas através do Teste de Tukey (5\% de significância).

As análises foram realizadas através dos procedimentos estatísticos SAS (Statistical Analysis System).

\subsubsection{Avaliação qualitativa dos resultados}

\subsubsection{Identificação dos fungos presentes}

Seguiu-se a identificação direta nos meios utilizados, após o período de incubação estabelecido. As colônias foram observadas em estereomicroscópio para observação do tipo e local das estruturas 
esporulantes. Para o exame microscópico foram preparadas lâminas em água e/ou coradas com lactofenol com pequenos pedaços das bordas das colônias, levando parte do micélio e das estruturas de frutificação, para observação das características morfológicas: tipo de micélio (septado ou não); estrutura (tamanho, cor e textura) do conidióforo e conídios/ esporângios e esporangióforos e estruturas de resistência (clamidosporos) ou estruturas contendo esporos como clestotécio.

Esses dados foram comparados às chaves de classificação dadas por Barnett \& Hunter (1972), Pitt \& Hocking (1997), Lacaz et al. (1998).

\subsubsection{Avaliação dos meios de cultivo e identificação dos fungos patogênicos e toxigênicos e estudo de bactérias}

Foram adquiridas culturas puras das espécies de fungos patogênicas e toxigênicas.

Durante as coletas da segunda fase foi conduzida, em paralelo, a inoculação das placas contendo os meios DRBC e Sabouraud com culturas puras de Aspergillus flavus, A. fumigatus, A. niger, A. parasiticus, Fusarium moniliforme, F. verticulloides, Histoplasma capsulatum e Stachybotrys chartarum. As placas foram incubadas durante sete dias em estufas separadas daquelas das coletas e monitoradas com relação ao crescimento e características morfológicas dos fungos durante o período de incubação. Esse acompanhamento teve como objetivos facilitar a identificação de uma possível presença destes fungos nos ambientes avaliados e certificar o crescimento dos mesmos nos meios DRBC e Sabouraud. 


\section{RESULTADOS E DISCUSSÃO}

\subsection{Avaliação quantitativa}

De acordo com os resultados obtidos, observa-se que houve diferença significativa na maioria dos locais amostrados entre os meios utilizados (Quadros 1 e 2), com exceção dos pontos produção de doce de leite da terceira coleta (Quadro 1) e empacotamento de embutidos da primeira coleta (Quadro 2). A primeira amostragem aponta o meio DRBC com melhor desempenho na indústria de doces nos dois pontos amostrados, área de produção de leite e amendoim (Quadro 1), tendo como meio de menor contagem de fungos o Extrato de Malte.

Na necessidade de trabalhar com um número maior de meios de cultura, optou-se por utilizar meios reconhecidos na área de alimentos. Desta forma foram conduzidas amostragens com os seguintes meios: DRBC, DG18, PCA-Cloranfenicol, BDA, MA e MEAYM. Duas amostragens foram conduzidas com os meios acima, uma correspondente à primeira coleta da área frigorífica (Quadro 2) e uma outra representando a segunda, da indústria de doces (Quadro 1). Na indústria de doces, o meio DRBC foi o que apresentou melhor desempenho, porém não houve diferença estatística com o DG18 na área de produção de doce de amendoim. Os meios MA, MEAYM e BDA aparecem significativamente, como os de menor performance quando testados em ambientes de produção de doces em geral (Quadro 1). 
Quando a Resolução - RE n 176 de 24 de outubro e 2000 do Ministério da Saúde do Brasil foi publicada, concluiu-se que era importante a inclusão do meio Sabouraud Dextrose a 4\% Ágar, indicado juntamente com BDA e MA, como os principais meios para amostragem de ar. Portanto, aquele meio foi incorporado nas demais coletas. O comportamento desses meios na indústria de doces apresentou diferença significativa apenas na área de amendoim, indicando o meio de MA e BDA como os de menor desempenho (Quadro 1). Já nas coletas da área frigorífica, o meio DRBC, embora apareça como o melhor na segunda coleta na área de empacotamento de embutidos, não difere estatisticamente do meio Sabouraud Dextrose a 4\% Ágar na área de produção de embutidos, sendo os de menor desempenho o PCACloranfenicol, BDA, MA e MEAYM (Quadro 2). 


\begin{tabular}{|c|c|c|c|c|}
\hline $\begin{array}{c}\text { Data } \\
\text { De coleta }\end{array}$ & Ambiente & $\begin{array}{l}\text { Meio de } \\
\text { Cultura }\end{array}$ & \multicolumn{2}{|c|}{$\mathrm{ufc} / \mathrm{m}^{3}$} \\
\hline \multirow[t]{8}{*}{ Mai/00 } & Produção de & DRBC & 1170 & \\
\hline & Doce de Leite & BDA & 680 & \\
\hline & & OGY & 652 & \\
\hline & & MA & 440 & $b$ \\
\hline & Produção de & DRBC & 1030 & \\
\hline & Doce de Amendoim & $\mathrm{BDA}$ & 872 & $a b$ \\
\hline & & OGY & 860 & $a b$ \\
\hline & & MA & 536 & $\mathrm{~b}$ \\
\hline \multirow[t]{12}{*}{ Ago/00 } & Produção de & DRBC & 6926 & \\
\hline & Doce de Leite & DG18 & 4611 & \\
\hline & & PCA-Clor & 4315 & \\
\hline & & BDA & 3510 & bc \\
\hline & & MA & 2961 & bc \\
\hline & & MEAYM & 2385 & $\mathrm{C}$ \\
\hline & Produção de & DRBC & 5080 & \\
\hline & Doce de Amendoim & DG18 & 4238 & $a b$ \\
\hline & & PCA-Clor & 3696 & $a b c$ \\
\hline & & BDA & 2698 & bcd \\
\hline & & MEAYM & 2141 & $\mathrm{~cd}$ \\
\hline & & MA & 1931 & d \\
\hline \multirow[t]{14}{*}{ Jan/01 } & Produção de & SABOURAUD & 1196 & \\
\hline & Doce de Leite & PCA-Clor & 1033 & a \\
\hline & & DRBC & 883 & a \\
\hline & & MEAYM & 770 & a \\
\hline & & BDA & 740 & a \\
\hline & & DG18 & 673 & $\mathrm{a}$ \\
\hline & & MA & 613 & $\underline{\mathrm{a}}$ \\
\hline & Produção de & DRBC & 1270 & \\
\hline & Doce de Amendoim & SABOURAUD & 1106 & a \\
\hline & & PCA-Clor & 1070 & $\mathrm{a}$ \\
\hline & & DG18 & 1036 & $a b$ \\
\hline & & MEAYM & 893 & $a b$ \\
\hline & & MA & 596 & bc \\
\hline & & BDA & 380 & c \\
\hline
\end{tabular}

Quadro 1 - Unidades formadoras de colônias $/ \mathrm{m}^{3}$ (valores médios) em diferentes meios de cultura, nos ambientes de produção de doce de leite e de amendoim.

${ }^{1}$ Médias seguidas da mesma letra na coluna não diferem entre si pelo teste de Tukey ( $5 \%$ de significância) 


\begin{tabular}{|c|c|c|c|c|}
\hline Data & Ambiente & Meio de & \multicolumn{2}{|c|}{$\mathrm{ufc} / \mathrm{m}^{3}$} \\
\hline \multirow[t]{2}{*}{ Set/00 } & $\begin{array}{c}\text { Empacotamento de } \\
\text { Embutidos }\end{array}$ & $\begin{array}{c}\text { MEAYM } \\
\text { DG18 } \\
\text { DRBC } \\
\text { PCA-Clor } \\
\text { BDA } \\
\text { MA } \\
\end{array}$ & $\begin{array}{l}563 \\
530 \\
523 \\
470 \\
383 \\
230 \\
\end{array}$ & $\begin{array}{l}a^{1} \\
a \\
a \\
a \\
a \\
a\end{array}$ \\
\hline & $\begin{array}{l}\text { Produção de } \\
\text { Embutidos }\end{array}$ & $\begin{array}{c}\text { MEAYM } \\
\text { BDA } \\
\text { PCA-Clor } \\
\text { DRBC } \\
\text { DG18 } \\
\text { MA }\end{array}$ & $\begin{array}{c}2300 \\
1573 \\
1210 \\
1003 \\
910 \\
390 \\
\end{array}$ & $\begin{array}{l}a \\
a b \\
b \\
b \\
b \\
c\end{array}$ \\
\hline \multirow[t]{2}{*}{ Dez/00 } & $\begin{array}{c}\text { Empacotamento de } \\
\text { Embutidos }\end{array}$ & $\begin{array}{c}\text { DRBC } \\
\text { DG18 } \\
\text { SABOURAUD } \\
\text { BDA } \\
\text { MEAYM } \\
\text { MA } \\
\text { PCA-Clor } \\
\end{array}$ & $\begin{array}{l}2246 \\
1130 \\
1126 \\
1106 \\
906 \\
656 \\
623 \\
\end{array}$ & $\begin{array}{l}a \\
b \\
b \\
b \\
b \\
b \\
b\end{array}$ \\
\hline & $\begin{array}{l}\text { Produção de } \\
\text { Embutidos }\end{array}$ & $\begin{array}{c}\text { SABOURAUD } \\
\text { DRBC } \\
\text { DG18 } \\
\text { MEAYM } \\
\text { MA } \\
\text { BDA } \\
\text { PCA-Clor }\end{array}$ & $\begin{array}{l}5703 \\
5696 \\
3040 \\
2456 \\
2143 \\
1876 \\
1503\end{array}$ & $\begin{array}{l}a \\
a b \\
b c \\
c \\
c \\
c \\
c\end{array}$ \\
\hline \multirow[t]{2}{*}{ Jan/01 } & $\begin{array}{c}\text { Empacotamento de } \\
\text { Embutidos }\end{array}$ & $\begin{array}{l}\text { SABOURAUD } \\
\text { DRBC } \\
\text { PCA-Clor } \\
\text { MA } \\
\text { MEAYM } \\
\text { BDA } \\
\text { DG18 }\end{array}$ & $\begin{array}{l}1410 \\
510 \\
473 \\
453 \\
366 \\
336 \\
300\end{array}$ & $\begin{array}{l}a \\
b \\
b \\
b \\
b \\
b \\
b\end{array}$ \\
\hline & $\begin{array}{l}\text { Produção de } \\
\text { Embutidos }\end{array}$ & $\begin{array}{c}\text { SABOURAUD } \\
\text { DRBC } \\
\text { MEAYM } \\
\text { PCA-Clor } \\
\text { MA } \\
\text { BDA } \\
\text { DG18 }\end{array}$ & $\begin{array}{l}2550 \\
1023 \\
866 \\
796 \\
730 \\
523 \\
490 \\
\end{array}$ & $\begin{array}{l}a \\
a b \\
b \\
b \\
b \\
b \\
b\end{array}$ \\
\hline
\end{tabular}

Quadro 2 - Unidades formadoras de colônias $/ \mathrm{m}^{3}$ (valores médios) em diferentes meios de cultura, nos ambientes de empacotamento e de produção de embutidos.

${ }^{1}$ Médias seguidas da mesma letra na coluna não diferem entre si pelo teste de Tukey ( $5 \%$ de significância) 
O Quadro 3 apresenta as contagens obtidas para os diferentes meios de cultura, em ufc/ $\mathrm{m}^{3}$, envolvendo todos os ambientes e épocas de coleta, podendo observar que os meios DRBC e Sabouraud Dextrose a 4\% Ágar se apresentam como os melhores para a realização de contagem de fungos no ar. Por outro lado, o meio de Malte mostrou-se, significativamente, como o menos indicado para o mesmo propósito.

\begin{tabular}{|c|c|cc|}
\hline $\begin{array}{c}\text { Meio de } \\
\text { Cultura }\end{array}$ & $\begin{array}{c}\text { Número de } \\
\text { repetições }\end{array}$ & \multicolumn{3}{|c|}{$\begin{array}{c}\text { Média } \\
\text { em ufc/m3 }\end{array}$} \\
\hline DRBC & 36 & 2280 & $\mathrm{a}^{1}$ \\
SABOURAUD & 18 & 2182 & $\mathrm{a}$ \\
DG18 & 30 & 1696 & $\mathrm{ab}$ \\
PCA-Clor & 30 & 1519 & $\mathrm{ab}$ \\
MEAYM & 30 & 1365 & $\mathrm{ab}$ \\
BDA & 36 & 1223 & $\mathrm{ab}$ \\
MA & 36 & 973 & $\mathrm{~b}$ \\
\hline Média Geral & & 1564 & \\
\hline Coeficiente de Variação em \% & 43,92 & \\
\hline \multicolumn{2}{|c|}{ Teste F } & $3,54^{\star *}$ \\
\hline
\end{tabular}

Quadro 3 - Contagem em ufc/ $\mathrm{m}^{3}$, de fungos, em diferentes meios de cultura envolvendo todos os ambientes e épocas de coleta.

${ }^{1}$ Médias seguidas da mesma letra na coluna não diferem entre si pelo teste de Tukey ( $5 \%$ de significância) 
O meio DRBC teve o mesmo desempenho em outros estudos, como nos desenvolvidos por King et al.(1979), motivo pelo qual este meio foi adotado pelos principais guias de microbiologia de alimentos (Acuff, 1992; Tournas et al.,1998). Estes resultados eram esperados devido à sua composição, que tem como inibidores a Rosa Bengala e o Dichloran, restringindo o tamanho das colônias e o Chloramphenicol como inibidor de bactérias. Esses fatos podem estar justificando que, em termos numéricos, o meio MA tenha tido o menor desempenho, uma vez que certos gêneros como, Crysonilia, Mucor e Rhizopus microrganismos que têm crescimento rápido, estiveram presentes, crescendo descontroladamente e dificultando o desenvolvimento de outros gêneros presentes.

Os resultados obtidos na segunda fase do projeto com os meios DRBC e Sabouraud estão apresentados nos Quadros 4 e 5. De modo geral os meios não diferiram estatisticamente durante as amostragens nas indústrias de doces e frigorífico. O meio DRBC apresentou melhor desempenho em duas coletas na área de empacotamento de embutidos e em uma coleta na área de produção de doce de leite. Tal fato pode estar relacionado com a peculiaridade do meio em restringir o crescimento de bactérias, proporcionando melhor desenvolvimento dos fungos, uma vez que uma alta incidência de bactérias principalmente na área de produção de embutidos, foi verificada durante a primeira fase do projeto (Quadro 18). 


\begin{tabular}{|c|c|c|cc|}
\hline $\begin{array}{c}\text { Data de } \\
\text { Coleta }\end{array}$ & Ambiente & $\begin{array}{c}\text { Meio de } \\
\text { cultura }\end{array}$ & \multicolumn{2}{|c|}{$\mathrm{ufc}^{3} \mathrm{~m}^{3}$} \\
\hline $20 / 06 / 01$ & $\begin{array}{c}\text { Produção de doce de } \\
\text { amendoim }\end{array}$ & DRBC & 370 & $\mathrm{a}^{1}$ \\
& SABOURAUD & 408 & $\mathrm{a}$ \\
\cline { 2 - 5 } & Produção de doce de & DRBC & 412 & $\mathrm{a}$ \\
& leite & SABOURAUD & 432 & $\mathrm{a}$ \\
\hline $27 / 06 / 01$ & Produção de doce de & DRBC & 440 & $\mathrm{a}$ \\
& amendoim & SABOURAUD & 452 & $\mathrm{a}$ \\
\cline { 2 - 5 } & Produção de doce de & DRBC & 658 & $\mathrm{a}$ \\
& leite & SABOURAUD & 460 & $\mathrm{~b}$ \\
\cline { 3 - 5 } $04 / 07 / 01$ & Drodução de doce de & DRBC & 1210 & $\mathrm{a}$ \\
& amendoim & SABOURAUD & 903 & $\mathrm{a}$ \\
\cline { 2 - 5 } & Produção de doce de & DRBC & 688 & $\mathrm{a}$ \\
& leite & SABOURAUD & 588 & $\mathrm{a}$ \\
\hline
\end{tabular}

Quadro 4 - Unidades formadoras de colônias/m3 (valores médios de cinco repetições) nos meios de cultura DRBC e Sabouraud, nos ambientes de produção de doce de leite e de amendoim.

${ }^{1}$ Médias seguidas da mesma letra na coluna não diferem entre si pelo teste de Tukey ( $5 \%$ de significância)

\begin{tabular}{|c|c|c|cc|}
\hline $\begin{array}{c}\text { Data de } \\
\text { Coleta }\end{array}$ & Ambiente & $\begin{array}{c}\text { Meio de } \\
\text { Cultura }\end{array}$ & \multicolumn{2}{|c|}{${\text { ufc } / \mathrm{m}^{3}}$} \\
\hline \multirow{2}{*}{$20 / 06 / 01$} & Empacotamento de & DRBC & 442 & $\mathrm{a}^{1}$ \\
& Embutidos & SABOURAUD & 282 & $\mathrm{~b}$ \\
\cline { 2 - 5 } & Produção de & DRBC & 512 & $\mathrm{a}$ \\
& Embutidos & SABOURAUD & 518 & $\mathrm{a}$ \\
\hline \multirow{2}{*}{$27 / 06 / 01$} & Empacotamento de & DRBC & 498 & $\mathrm{a}$ \\
& Embutidos & SABOURAUD & 466 & $\mathrm{a}$ \\
\cline { 2 - 5 } & Produção de & DRBC & 722 & $\mathrm{a}$ \\
& Embutidos & SABOURAUD & 475 & $\mathrm{a}$ \\
\cline { 3 - 5 } & Empacotamento de & DRBC & 1654 & $\mathrm{a}$ \\
& Embutidos & SABOURAUD & 828 & $\mathrm{~b}$ \\
\cline { 3 - 5 } & Produção de & DRBC & 1454 & $\mathrm{a}$ \\
& Embutidos & SABOURAUD & 1068 & $\mathrm{a}$ \\
\hline
\end{tabular}

Quadro 5 - Unidades formadoras de colônias $/ \mathrm{m}^{3}$ (valores médios de cinco repetições) nos meios de cultura DRBC e Sabouraud, nos ambientes de empacotamento e de produção de embutidos.

${ }^{1}$ Médias seguidas da mesma letra na coluna não diferem entre si pelo teste de Tukey ( $5 \%$ de significância) 


\subsection{Avaliação qualitativa}

A avaliação qualitativa visou na primeira fase, identificar os gêneros de maior ocorrência e presentes no período estipulado de incubação, isto é, foram identificados somente aqueles que apresentaram suas estruturas de frutificação necessárias para sua identificação.

Assim, os Quadros de 6 a 9 apresentam os gêneros de fungos encontrados nos meios avaliados. O gênero Cladosporium, comum em ambientes interiores que não apresentam problemas de saúde (Lacaz, 1970; Padrão Referencial Brasileiro Microbiológico, 1998), foi encontrado nos ambientes avaliados crescendo em $100 \%$ dos meios testados. Dos gêneros encontrados nos períodos de avaliação, apenas dois deles podem conter espécies toxigênicas indesejáveis para qualquer ambiente (Padrão Referencial Brasileiro Microbiológico, 1998), a saber: Aspergillus e Fusarium. Quanto ao outro gênero toxigênico citado, o Stachybotrys e os patogênicos dos gêneros Histoplasma, Cryptococcus e Paracoccidioides, esses não puderam ser detectados em nenhum dos meios empregados no período de avaliação considerado, porque se estiveram presentes, não apresentaram as características morfológicas necessárias à sua identificação. 


\begin{tabular}{|c|c|c|c|c|c|c|c|c|c|}
\hline \multirow[b]{2}{*}{ GÊNEROS } & \multicolumn{9}{|c|}{ MEIOS DE CULTURA } \\
\hline & MA & MEAYM & BDA & DRBC & DG18 & $\underline{\text { PCA-Clor }}$ & SABOURAUD & $\% M / G^{1}$ & $\% \mathrm{C} / \mathrm{TC}^{2}$ \\
\hline Aspergillus & 2 & 2 & 3 & 2 & 1 & 1 & 1 & 100 & 75 \\
\hline Cladosporium & 2 & 2 & 2 & 3 & 2 & 2 & 1 & 100 & 87 \\
\hline Chrysonilia & 1 & 1 & 1 & 3 & 2 & 1 & 0 & 86 & 56 \\
\hline Trichoderma & 1 & 2 & 2 & 1 & 1 & 0 & 1 & 86 & 50 \\
\hline Mucor & 2 & 1 & 2 & 0 & 0 & 0 & 0 & 43 & 31 \\
\hline Penicillium & 0 & 2 & 2 & 1 & 2 & 1 & 1 & 86 & 56 \\
\hline Paecilomyces & 0 & 0 & 1 & 0 & 0 & 0 & 0 & 14 & 6 \\
\hline Rhizopus & 0 & 0 & 1 & 0 & 0 & 0 & 0 & 14 & 6 \\
\hline Total de Coleta/Meio & 3 & 2 & 3 & 3 & 2 & 2 & 1 & & \\
\hline
\end{tabular}

Quadro 6 - Gêneros de fungos desenvolvidos em diferentes meios de cultura no ambiente de produção de doce de leite.

${ }^{1} \% \mathrm{M} / \mathrm{G}=\%$ de meios de cultura que permitiu o crescimento do gênero em relação ao número total de meios de cultura testados.

$2 \% \mathrm{C} / \mathrm{TC}=\%$ de coletas onde ocorreu a presença do gênero em relação ao número total de coletas realizadas. 


\begin{tabular}{|c|c|c|c|c|c|c|c|c|c|}
\hline \multirow[b]{2}{*}{ GÊNEROS } & \multicolumn{9}{|c|}{ MEIOS DE CULTURA } \\
\hline & MA & MEYAM & BDA & DRBC & DG18 & PCA-Clor & SABOURAUD & $\% \mathrm{M} / \mathrm{G}^{1}$ & $\% \mathrm{C} / \mathrm{TC}^{2}$ \\
\hline Aspergillus & 3 & 2 & 3 & 2 & 2 & 1 & 1 & 100 & 88 \\
\hline Cladosporium & 3 & 2 & 3 & 3 & 2 & 2 & 1 & 100 & 100 \\
\hline Chrysonilia & 1 & 0 & 1 & 1 & 2 & 0 & 0 & 57 & 31 \\
\hline Trichoderma & 3 & 1 & 1 & 0 & 2 & 0 & 1 & 71 & 50 \\
\hline Mucor & 1 & 1 & 1 & 0 & 1 & 1 & 0 & 71 & 31 \\
\hline Penicillium & 2 & 2 & 3 & 2 & 1 & 0 & 0 & 71 & 62 \\
\hline Paecilomyces & 0 & 0 & 0 & 1 & 0 & 0 & 0 & 14 & 6 \\
\hline Rhizopus & 1 & 1 & 1 & 1 & 0 & 0 & 1 & 71 & 31 \\
\hline Fusarium & 0 & 0 & 1 & 0 & 0 & 0 & 0 & 14 & 6 \\
\hline Aerobasidium & 0 & 0 & 1 & 0 & 0 & 0 & 0 & 14 & 6 \\
\hline Total de Coleta/Meio & 3 & 2 & 3 & 3 & 2 & 2 & 1 & & \\
\hline
\end{tabular}

Quadro 7 - Gêneros de fungos desenvolvidos em diferentes meios de cultura no ambiente de produção de doce de amendoim.

$1 \% \mathrm{M} / \mathrm{G}=\%$ de meios de cultura que permitiu o crescimento do gênero em relação ao número total de meios de cultura testados.

$2 \% \mathrm{C} / \mathrm{TC}=\%$ de coletas onde ocorreu a presença do gênero em relação ao número total de coletas realizadas. 


\begin{tabular}{|c|c|c|c|c|c|c|c|c|c|}
\hline \multirow[b]{2}{*}{ GÊNEROS } & \multicolumn{9}{|c|}{ MEIOS DE CULTURA } \\
\hline & MA & MEAYM & BDA & DRBC & DG18 & PCA-Clor & SABOURAUD & $\% \mathrm{M} / \mathrm{G}^{1}$ & $\% \mathrm{C} / \mathrm{TC}^{2}$ \\
\hline Aspergillus & 0 & 1 & 1 & 0 & 0 & 2 & 0 & 43 & 22 \\
\hline Cladosporium & 3 & 3 & 2 & 3 & 3 & 3 & 1 & 100 & 100 \\
\hline Chrysonilia & 2 & 1 & 0 & 2 & 1 & 1 & 0 & 71 & 39 \\
\hline Trichoderma & 1 & 1 & 0 & 0 & 0 & 0 & 0 & 28 & 11 \\
\hline Alternaria & 1 & 1 & 0 & 0 & 0 & 0 & 0 & 28 & 11 \\
\hline Mucor & 1 & 0 & 0 & 0 & 1 & 0 & 0 & 28 & 11 \\
\hline Penicillium & 1 & 1 & 2 & 1 & 3 & 0 & 1 & 86 & 50 \\
\hline Paecilomyces & 0 & 0 & 0 & 0 & 1 & 0 & 0 & 14 & 5 \\
\hline Rhizopus & 0 & 0 & 0 & 1 & 0 & 0 & 0 & 14 & 5 \\
\hline Curvularia & 2 & 0 & 0 & 1 & 0 & 1 & 0 & 43 & 22 \\
\hline Total de Coleta/Meio & 3 & 3 & 2 & 3 & 3 & 3 & 1 & & \\
\hline
\end{tabular}

Quadro 8 - Gêneros de fungos desenvolvidos em diferentes meios de cultura no ambiente de empacotamento de embutidos.

$1 \% \mathrm{M} / \mathrm{G}=\%$ de meios de cultura que permitiu o crescimento do gênero em relação ao número total de meios de cultura testados.

$2 \% \mathrm{C} / \mathrm{TC}=\%$ de coletas onde ocorreu a presença do gênero em relação ao número total de coletas realizadas. 


\begin{tabular}{|c|c|c|c|c|c|c|c|c|c|}
\hline \multirow[b]{2}{*}{ GÊNEROS } & \multicolumn{9}{|c|}{ MEIOS DE CULTURA } \\
\hline & MA & MEAYM & BDA & DRBC & DG18 & PCA-Clor & SABOURAUD & $\% \mathrm{M} / \mathrm{G}^{1}$ & $\% \mathrm{C} / \mathrm{TC}^{2}$ \\
\hline Aspergillus & 1 & 2 & 1 & 0 & 1 & 0 & 0 & 57 & 28 \\
\hline Cladosporium & 3 & 3 & 2 & 3 & 3 & 3 & 1 & 100 & 100 \\
\hline Chrysonilia & 0 & 0 & 0 & 2 & 0 & 0 & 1 & 28 & 17 \\
\hline Trichoderma & 0 & 1 & 0 & 0 & 1 & 0 & 0 & 28 & 11 \\
\hline Alternaria & 1 & 1 & 1 & 0 & 1 & 0 & 0 & 57 & 22 \\
\hline Mucor & 0 & 0 & 0 & 1 & 0 & 0 & 0 & 14 & 5 \\
\hline Penicillium & 2 & 3 & 2 & 1 & 3 & 1 & 1 & 100 & 72 \\
\hline Paecilomyces & 1 & 1 & 0 & 1 & 1 & 0 & 0 & 57 & 22 \\
\hline Rhizopus & 0 & 1 & 0 & 0 & 0 & 0 & 0 & 14 & 5 \\
\hline Curvularia & 1 & 1 & 0 & 1 & 0 & 1 & 0 & 57 & 22 \\
\hline Total de Coleta/Meio & 3 & 3 & 2 & 3 & 3 & 3 & 1 & & \\
\hline
\end{tabular}

Quadro 9 - Gêneros de fungos desenvolvidos em diferentes meios de cultura no ambiente de produção de embutidos.

$1 \% \mathrm{M} / \mathrm{G}=\%$ de meios de cultura que permitiu o crescimento do gênero em relação ao número total de meios de cultura testados.

$2 \% \mathrm{C} / \mathrm{TC}=\%$ de coletas onde ocorreu a presença do gênero em relação ao número total de coletas realizadas. 
Face à diversidade de gêneros identificados em cada um dos meios utilizados, torna-se difícil afirmar qual meio seria o mais indicado para o isolamento de determinado gênero de fungo. Somente em termos quantitativos é que este trabalho permite identificar meios melhores para o isolamento de fungos.

Os Quadros de 10 a 17 mostram que espécies indesejáveis como Aspergillus flavus, A. fumigatus, A. niger, A. parasiticus, Fusarium moniliforme, F. verticulloides, Histoplasma capsulatum e Stachybotrys chartarum podem crescer nos meios Sabourand e DRBC, isto quando inoculadas sem a presença de outros gêneros de fungos. Para a identificação de fungos, é de grande importância se conhecer a ocorrência de diferentes cores e tonalidades das colônias em cada meio de cultivo, devido ao grande valor das características morfológicas/culturais na identificação dos mesmos.

$\mathrm{Na}$ segunda fase, a espécie Aspergillus flavus foi isolada a partir do meio Sabouraud no ambiente da indústria de alimentos, na área de processamento de doces de amendoim, sendo identificada no meio Aspergillus Flavus Parisiticus Ágar (Vanderzant \& Splittstoesser, 1992). 


\begin{tabular}{|c|c|c|c|c|c|c|c|}
\hline Espécie & \multicolumn{7}{|c|}{ Aspergillus parasiticus } \\
\hline Meio de Cultura & \multicolumn{7}{|c|}{ DRBC } \\
\hline Incubação em dias & $1^{0}$ & $2^{0}$ & $3^{0}$ & $4^{0}$ & $5^{0}$ & $6^{\circ}$ & $7^{0}$ \\
\hline diâmetro da colônia & $4,2 \mathrm{~mm}$ & $1,51 \mathrm{~cm}$ & $2,1 \mathrm{~cm}$ & $2,8 \mathrm{~cm}$ & $3,0 \mathrm{~cm}$ & $3,83 \mathrm{~cm}$ & $4,12 \mathrm{~cm}$ \\
\hline cor & branco & branco & $\begin{array}{c}\text { amarelo } \\
\text { claro }\end{array}$ & $\begin{array}{c}\text { amarelo } \\
\text { claro }\end{array}$ & amarelo & amarelo & marrom \\
\hline Meio de Cultura & \multicolumn{7}{|c|}{ SABOURAUD } \\
\hline Incubação em dias & $1^{0}$ & $2^{0}$ & $3^{\circ}$ & $4^{\circ}$ & $5^{\circ}$ & $6^{\circ}$ & $7^{0}$ \\
\hline diâmetro da colônia & $8,8 \mathrm{~mm}$ & $2,63 \mathrm{~cm}$ & $4,43 \mathrm{~cm}$ & $5,33 \mathrm{~cm}$ & \multicolumn{3}{|c|}{ tomou a placa } \\
\hline cor & branco & branco & branco & branco & branco & amarelo & amarelo \\
\hline
\end{tabular}

Quadro 10 - Diâmetro e cor das colônias de Aspergillus parasiticus ao longo do período de incubação.

\begin{tabular}{|c|c|c|c|c|c|c|c|}
\hline Espécie & \multicolumn{7}{|c|}{ Aspergillus fumigatus } \\
\hline Meio de Cultura & \multicolumn{7}{|c|}{ DRBC } \\
\hline Incubação em dias & $1^{0}$ & $2^{0}$ & $3^{0}$ & $4^{\circ}$ & $5^{0}$ & $6^{0}$ & $7^{0}$ \\
\hline diâmetro da colônia & 0 & 0 & $5,5 \mathrm{~mm}$ & $1,08 \mathrm{~cm}$ & $2,16 \mathrm{~cm}$ & $2,8 \mathrm{~cm}$ & $3,0 \mathrm{~cm}$ \\
\hline cor & . & . & rosa & branco & branco & branco & branco \\
\hline Meio de Cultura & \multicolumn{7}{|c|}{ SABOURAUD } \\
\hline Incubação em dias & $1^{0}$ & $2^{0}$ & $3^{0}$ & $4^{\circ}$ & $5^{0}$ & $6^{0}$ & $7^{0}$ \\
\hline diâmetro da colônia & 0 & $8,0 \mathrm{~mm}$ & $2,1 \mathrm{~cm}$ & $3,33 \mathrm{~cm}$ & $5,41 \mathrm{~cm}$ & $6,6 \mathrm{~cm}$ & $\begin{array}{c}\text { tomou a } \\
\text { placa }\end{array}$ \\
\hline cor & 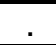 & branco & branco & branco & branco & branco & branco \\
\hline
\end{tabular}

Quadro 11 - Diâmetro e cor das colônias de Aspergillus fumigatus ao longo do período de incubação. 


\begin{tabular}{|c|c|c|c|c|c|c|c|}
\hline Espécie & \multicolumn{7}{|c|}{ Aspergillus niger } \\
\hline Meio de Cultura & \multicolumn{7}{|c|}{ DRBC } \\
\hline Incubação em dias & $1^{0}$ & $2^{0}$ & $3^{0}$ & $4^{\circ}$ & $5^{0}$ & $6^{0}$ & $7^{0}$ \\
\hline diâmetro da colônia & $5,7 \mathrm{~mm}$ & $1,25 \mathrm{~cm}$ & $2,52 \mathrm{~cm}$ & $3,74 \mathrm{~cm}$ & $5,0 \mathrm{~cm}$ & \multicolumn{2}{|c|}{ tomou a placa } \\
\hline cor & branco & $\begin{array}{c}\text { amarelo } \\
\text { claro }\end{array}$ & $\begin{array}{c}\text { amarelo } \\
\text { claro }\end{array}$ & $\begin{array}{c}\text { amarelo } \\
\text { claro }\end{array}$ & preto & preto & preto \\
\hline Meio de Cultura & \multicolumn{7}{|c|}{ SABOURAUD } \\
\hline Incubação em dias & $1^{0}$ & $2^{0}$ & $3^{0}$ & $4^{\circ}$ & $5^{0}$ & $6^{0}$ & $7^{0}$ \\
\hline diâmetro da colônia & $9,0 \mathrm{~mm}$ & $3,1 \mathrm{~cm}$ & $6,0 \mathrm{~cm}$ & $7,71 \mathrm{~cm}$ & \multicolumn{3}{|c|}{ tomou a placa } \\
\hline cor & branco & $\begin{array}{c}\text { amarelo } \\
\text { claro }\end{array}$ & $\begin{array}{c}\text { centro } \\
\text { amarelo } \\
\text { com pontos } \\
\text { pretos e } \\
\text { borda } \\
\text { branca }\end{array}$ & $\begin{array}{c}\text { centro } \\
\text { amarelo } \\
\text { com pontos } \\
\text { pretos e } \\
\text { borda } \\
\text { branca }\end{array}$ & preto & preto & preto \\
\hline
\end{tabular}

Quadro 12 - Diâmetro e cor das colônias de Aspergillus niger ao longo do período de incubação.

\begin{tabular}{|c|c|c|c|c|c|c|c|}
\hline Espécie & \multicolumn{7}{|c|}{ Aspergillus flavus } \\
\hline Meio de Cultura & \multicolumn{7}{|c|}{ DRBC } \\
\hline Incubação em dias & $1^{0}$ & $2^{0}$ & $3^{0}$ & $4^{\circ}$ & $5^{0}$ & $6^{0}$ & $7^{0}$ \\
\hline diâmetro da colônia & $3,1 \mathrm{~mm}$ & $8,5 \mathrm{~mm}$ & $1,35 \mathrm{~cm}$ & $2,1 \mathrm{~cm}$ & $3,17 \mathrm{~cm}$ & $4,06 \mathrm{~cm}$ & $4,06 \mathrm{~cm}$ \\
\hline cor & branco & $\begin{array}{c}\text { amarelo } \\
\text { claro }\end{array}$ & $\begin{array}{c}\text { amarelo } \\
\text { claro }\end{array}$ & $\begin{array}{c}\text { amarelo } \\
\text { claro }\end{array}$ & amarelo & marrom & marrom \\
\hline Meio de Cultura & \multicolumn{7}{|c|}{ SABOURAUD } \\
\hline Incubação em dias & $1^{0}$ & $2^{0}$ & $3^{0}$ & $4^{\circ}$ & $5^{0}$ & $6^{0}$ & $7^{0}$ \\
\hline diâmetro da colônia & $5,5 \mathrm{~mm}$ & $1,64 \mathrm{~cm}$ & $2,45 \mathrm{~cm}$ & $3,48 \mathrm{~cm}$ & $4,0 \mathrm{~cm}$ & $4,95 \mathrm{~cm}$ & $4,95 \mathrm{~cm}$ \\
\hline cor & branco & branco & $\begin{array}{c}\text { amarelo } \\
\text { claro }\end{array}$ & $\begin{array}{c}\text { amarelo } \\
\text { claro }\end{array}$ & amarelo & marrom & marrom \\
\hline
\end{tabular}

Quadro 13 - Diâmetro e cor das colônias de Aspergillus flavus ao longo do período de incubação. 


\begin{tabular}{|c|c|c|c|c|c|c|c|}
\hline Espécie & \multicolumn{7}{|c|}{ Fusarium verticulloides } \\
\hline Meio de Cultura & \multicolumn{7}{|c|}{ DRBC } \\
\hline Incubação em dias & 10 & $2^{0}$ & $3^{0}$ & $4^{\circ}$ & $5^{0}$ & $6^{0}$ & $7^{0}$ \\
\hline diâmetro da colônia & $3,0 \mathrm{~mm}$ & $6,7 \mathrm{~mm}$ & $1,2 \mathrm{~cm}$ & $1,76 \mathrm{~cm}$ & $2,04 \mathrm{~cm}$ & $2,55 \mathrm{~cm}$ & $3,43 \mathrm{~cm}$ \\
\hline cor & branco & branco & rosa claro & rosa claro & rosa claro & lilás & lilás \\
\hline Meio de Cultura & \multicolumn{7}{|c|}{ SABOURAUD } \\
\hline Incubação em dias & 10 & $2^{0}$ & 3은 & $4^{0}$ & 50 & 6o & $7^{0} \underline{0}$ \\
\hline diâmetro da colônia & $3,0 \mathrm{~mm}$ & $1,67 \mathrm{~cm}$ & $2,89 \mathrm{~cm}$ & $3,91 \mathrm{~cm}$ & $4,45 \mathrm{~cm}$ & $4,72 \mathrm{~cm}$ & $\begin{array}{c}\text { tomou a } \\
\text { placa }\end{array}$ \\
\hline cor & branco & branco & rosa claro & rosa claro & rosa claro & lilás & lilás \\
\hline
\end{tabular}

Quadro 14 - Diâmetro e cor das colônias de Fusarium verticulloides ao longo do período de incubação.

\begin{tabular}{|c|c|c|c|c|c|c|c|}
\hline Espécie & \multicolumn{7}{|c|}{ Fusarium moniliforme } \\
\hline Meio de Cultura & \multicolumn{7}{|c|}{ DRBC } \\
\hline Incubação em dias & $1^{0}$ & $2^{0}$ & $3^{\circ}$ & $4^{\circ}$ & $5^{0}$ & $6^{0}$ & $7^{0}$ \\
\hline diâmetro da colônia & $3,0 \mathrm{~mm}$ & $1,1 \mathrm{~cm}$ & $1,84 \mathrm{~cm}$ & $2,37 \mathrm{~cm}$ & $2,52 \mathrm{~cm}$ & $3,31 \mathrm{~cm}$ & $3,93 \mathrm{~cm}$ \\
\hline cor & branco & branco & $\begin{array}{c}\text { centro } \\
\text { branco e } \\
\text { borda rosa }\end{array}$ & $\begin{array}{c}\text { centro } \\
\text { branco e } \\
\text { borda rosa }\end{array}$ & $\begin{array}{c}\text { centro } \\
\text { branco e } \\
\text { borda rosa }\end{array}$ & $\begin{array}{c}\text { amarelo } \\
\text { claro }\end{array}$ & amarelo \\
\hline Meio de Cultura & \multicolumn{7}{|c|}{ SABOURAUD } \\
\hline Incubação em dias & $1^{0}$ & $2^{0}$ & $3^{\circ}$ & $4^{\circ} \stackrel{0}{ }$ & $5^{\circ}$ & $6^{0}$ & $7^{0} \underline{-}$ \\
\hline diâmetro da colônia & $4,2 \mathrm{~mm}$ & $2,47 \mathrm{~cm}$ & $4,1 \mathrm{~cm}$ & $5,76 \mathrm{~cm}$ & $6,95 \mathrm{~cm}$ & $7,52 \mathrm{~cm}$ & $\begin{array}{c}\text { tomou a } \\
\text { placa }\end{array}$ \\
\hline cor & branco & branco & branco & branco & branco & $\begin{array}{c}\text { amarelo } \\
\text { claro }\end{array}$ & $\begin{array}{c}\text { amarelo } \\
\text { claro }\end{array}$ \\
\hline
\end{tabular}

Quadro 15 - Diâmetro e cor das colônias de Fusarium moniliforme ao longo do período de incubação. 


\begin{tabular}{|c|c|c|c|c|c|c|c|}
\hline Espécie & \multicolumn{7}{|c|}{ Stachybotrys chartarum } \\
\hline Meio de Cultura & \multicolumn{7}{|c|}{ DRBC } \\
\hline Incubação em dias & $1^{0}$ & $2^{0}$ & $3^{0}$ & $4^{0}$ & $5^{0}$ & $6^{0}$ & $7^{0}$ \\
\hline diâmetro da colônia & $1,6 \mathrm{~mm}$ & $4,3 \mathrm{~mm}$ & $6,1 \mathrm{~mm}$ & $6,5 \mathrm{~mm}$ & $6,5 \mathrm{~mm}$ & $8,87 \mathrm{~mm}$ & $8,87 \mathrm{~mm}$ \\
\hline cor & $\begin{array}{l}\text { levemente } \\
\text { marrom }\end{array}$ & $\begin{array}{c}\text { levemente } \\
\text { marrom }\end{array}$ & $\begin{array}{c}\text { marrom } \\
\text { claro }\end{array}$ & $\begin{array}{l}\text { marrom } \\
\text { claro }\end{array}$ & $\begin{array}{c}\text { marrom } \\
\text { claro }\end{array}$ & marrom & marrom \\
\hline Meio de Cultura & \multicolumn{7}{|c|}{ SABOURAUD } \\
\hline Incubação em dias & $1^{0}$ & $2^{0}$ & $3^{0}$ & $4^{\circ}$ & $5^{0}$ & $6^{0}$ & $7^{0}$ \\
\hline diâmetro da colônia & $1,6 \mathrm{~mm}$ & $4,0 \mathrm{~mm}$ & $6,4 \mathrm{~mm}$ & $7,9 \mathrm{~mm}$ & $7,9 \mathrm{~mm}$ & $10,17 \mathrm{~mm}$ & $10,17 \mathrm{~mm}$ \\
\hline cor & $\begin{array}{c}\text { levemente } \\
\text { marrom }\end{array}$ & $\begin{array}{c}\text { levemente } \\
\text { marrom }\end{array}$ & $\begin{array}{c}\text { marrom } \\
\text { claro }\end{array}$ & $\begin{array}{c}\text { marrom } \\
\text { claro }\end{array}$ & $\begin{array}{c}\text { marrom } \\
\text { claro }\end{array}$ & marrom & marrom \\
\hline
\end{tabular}

Quadro 16 - Diâmetro e cor das colônias de Stachybotrys chartarum ao longo do período de incubação.

\begin{tabular}{|c|c|c|c|c|c|c|c|}
\hline Espécie & \multicolumn{7}{|c|}{ Histoplasma capsulatum } \\
\hline Meio de Cultura & \multicolumn{7}{|c|}{ DRBC } \\
\hline Incubação em dias & 10 & $2^{0}$ & $3^{0}$ & $4^{\circ}$ & $5^{0}$ & $6^{0}$ & $7^{\circ}$ \\
\hline diâmetro da colônia & $1,9 \mathrm{~mm}$ & $6,1 \mathrm{~mm}$ & $1,4 \mathrm{~cm}$ & $1,59 \mathrm{~cm}$ & $1,89 \mathrm{~cm}$ & $1,89 \mathrm{~cm}$ & $2,0 \mathrm{~cm}$ \\
\hline cor & branco & branco & branco & branco & branco & $\begin{array}{l}\text { levemente } \\
\text { verde }\end{array}$ & $\begin{array}{l}\text { levemente } \\
\text { verde }\end{array}$ \\
\hline Meio de Cultura & \multicolumn{7}{|c|}{ SABOURAUD } \\
\hline Incubação em dias & $1^{0}$ & $2^{0}$ & $3^{0}$ & $4^{0}$ & $5^{0}$ & $6^{0}$ & $7^{0}$ \\
\hline diâmetro da colônia & $3,4 \mathrm{~mm}$ & $6,85 \mathrm{~mm}$ & $1,15 \mathrm{~cm}$ & $2 \mathrm{~cm}$ & $2,31 \mathrm{~cm}$ & $2,31 \mathrm{~cm}$ & $2,7 \mathrm{~cm}$ \\
\hline cor & branco & branco & branco & branco & branco & $\begin{array}{l}\text { levemente } \\
\text { verde }\end{array}$ & $\begin{array}{l}\text { levemente } \\
\text { verde }\end{array}$ \\
\hline
\end{tabular}

Quadro 17- Diâmetro e cor das colônias de Histoplasma capsulatum ao longo do período de incubação. 


\subsection{Avaliação da contagem total de bactérias}

Tendo em vista, que poucos pesquisadores no mundo sugeriram padrões referenciais em relação à qualidade microbiológica do ar, para estruturas bacterianas, a presente pesquisa, coletou dados que podem vir a ser úteis, por ocasião de estudos para estabelecimento de padrões nacionais.

Segundo Padrão Referencial Brasileiro Microbiológico (1998), os ambientes não apresentam situações problemáticas, quando bactérias Gram-positivas, como Micrococcus sp, Streptococcus sp e Staphylococcus $\mathrm{sp}$ predominarem no ambiente, em populações abaixo de $200 \mathrm{ufc} / \mathrm{m}^{3}$. Apesar de não ter sido realizado o teste Gram, os ambientes avaliados apresentaram populações de bactérias que merecem atenção especial pelos altos valores observados.

No Quadro 18 são apresentadas as contagens de bactérias $\left(\mathrm{ufc} / \mathrm{m}^{3}\right)$ nos ambientes estudados.

\begin{tabular}{|c|c|c|}
\hline \multirow{2}{*}{$\begin{array}{c}\text { Data de } \\
\text { coleta }\end{array}$} & \multicolumn{2}{|c|}{ Ambientes } \\
\cline { 2 - 3 } Mai/00 & 622 & Doce de leite \\
\hline Ago/00 & 331 & 645 \\
\hline Jan/01 & 426 & 223 \\
\hline \multirow{2}{*}{$\begin{array}{c}\text { Data de } \\
\text { coleta }\end{array}$} & \multicolumn{2}{|c|}{ Ambientes } \\
\cline { 2 - 3 } Set/00 & 820 & 446 \\
\hline Dez/00 & 2380 & 906 \\
\hline Jan/01 & 3946 & 2926 \\
\hline
\end{tabular}

Quadro 18 - Unidades formadoras de colônias $/ \mathrm{m}^{3}$ (valores médios) de bactérias nos diferentes ambientes amostrados (médias de três repetições). 
Nos ambientes estudados foram encontrados médias, entre as três coletas, de 449 e 2239 ufc de bactérias $/ \mathrm{m}^{3}$, para indústria de doces e frigorífico, respectivamente. Os dados encontrados sugerem que novos estudos sejam realizados, no sentido de caminhar para um padrão referencial que possa ser utilizado no monitoramento dos ambientes de processamento de alimentos.

\subsection{Avaliação ambiental das instalações amostradas}

O parâmetro empregado na avaliação ambiental restringiu-se aos resultados de contagem de propágulos de fungos, em valores absolutos, considerando-se que um ambiente está em boas condições, se apresentar valor de contagem igual ou menor que $750 \mathrm{ufc} / \mathrm{m}^{3}$ e não houver espécies toxigênicas e ou patogênicas (Resolução n ${ }^{0} 176$ ).

Partindo deste princípio, os meios de cultura que apresentaram baixa contagem estariam na maioria dos casos avaliando os ambientes amostrados como em boas condições (Quadros 1 e 2), o que de fato não é o real, pois quando se consideram as contagens em DRBC e Sabouraud Dextrose a 4\% Agar, esses mesmos ambientes tornam-se passíveis de avaliação quanto à fonte de contaminação e preocupação quanto à possibilidade de ocorrência de patógenos indesejáveis.

Devido ao fato destes ambientes não serem totalmente climatizados, a relação ambiental externo/interno não foi considerada.

As altas contagens de fungos encontradas constituem-se em fato preocupante, pois, apesar de muitos não pertencerem a gêneros com potencial de patogenicidade e/ou toxicidade, a ocorrência de A. flavus torna o ambiente de risco para os produtos e manipuladores, e a preocupação ainda mais relevante. A presença do gênero Aspergillus na área de produção de doces, principalmente na área de produção do doce 
de amendoim, onde a espécie toxigênica $A$. flavus esteve presente, tornase preocupante pelo fato de que os esporos e fragmentos de micélio podem conter altas concentrações de toxinas, sendo a inalação desses na colheita do milho e do amendoim, ou no trabalho em plantas de processamento, relatada na indução do câncer de fígado, além de toxicidade aguda (World Health Organization, 1988).

De acordo com os padrões de Kurata (1994) os ambientes estudados estariam altamente comprometidos, pois classificou os ambientes de processamento e empacotamento de alimento como ruins acima de $100 \mathrm{ufc} / \mathrm{m}^{3}$. As contagens de fungos no presente trabalho variaram de 230 a $6926 \mathrm{ufc} / \mathrm{m}^{3}$, encontradas nos meios MA e DRBC, respectivamente.

Considerando as condições dos ambientes estudados no presente trabalho, torna-se necessário que padrões brasileiros de contaminação biológica em ambientes industriais sejam estabelecidos para seu monitoramento. Além disso, a arquitetura das instalações deve ser revista, com soluções principalmente para pequenas e médias empresas dentro da realidade do nosso país, visando minimizar tanto os efeitos nocivos à saúde, como econômicos que este quadro pode representar.

Os ambientes estudados não apresentam um fluxograma que proporcione condições satisfatórias no processamento e empacotamento dos produtos, tanto na indústria de doces como no frigorífico. $\mathrm{Na}$ indústria de doces o recebimento da matéria-prima para o doce de amendoim, ou seja, o amendoim em grãos é recebido e processado na mesma planta em que os doces são processados e empacotados. Ainda, circuladores de ar ajudam a dispersar as fontes poluentes por toda a fábrica. Já no frigorífico, a alta umidade faz desenvolver fontes de contaminação microbiana pelo teto e parte das paredes que não possuem revestimento apropriado. 


\section{CONCLUSÕES}

De acordo com os resultados obtidos, pode-se concluir que entre os meios utilizados para quantificação de fungos no ar, 'Dichloran Rose Bengal Chloramphenicol Agar" (DRBC) e "Sabouraud Dextrose a 4\% Agar" devem ser recomendados para a avaliação quantitativa de fungos, no ar, de ambientes interiores. Sugere-se que a Resolução 176 de 28 de outubro de 2000 seja revista quanto à recomendação do meio de Malte para coletas ambientais, pois o mesmo se apresentou como o de menor desempenho dentre todos os meios avaliados.

Dentre os meios estudados não foi possível concluir sobre o melhor para a identificação de fungos, no entanto, pode-se recomendar o meio DRBC, principalmente em situações de alta concentração de bactérias e fungos de crescimento rápido que podem comprometer a avaliação. Ainda, reprova-se o PCA- cloranfenicol que apresentou a mais baixa diversidade de gêneros.

A dificuldade na identificação dos gêneros e espécies presentes em tempo reduzido é problemática, uma vez que, respostas para medidas corretivas de controle devem ser imediatas. Assim, estudos na área molecular, como desenvolvimento de primers específicos para a identificação de fungos de interesse à saúde, tornam-se uma ferramenta indispensável para auxiliar o monitoramento dos ambientes.

A necessidade de caminhar para um padrão referencial nacional para monitoramento microbiológico de ambientes de processamento e 
empacotamento de alimentos é indispensável e urgente, uma vez que a avaliação quali-quantitativa dos ambientes estudados mostrou que estes não se encontram em boas condições ambientais, quanto à contaminação microbiana.

No geral, as instalações estudadas devem ajustar o fluxograma do processo industrial, como separar as áreas de recebimento de matériaprima, processamento e empacotamento, pois não apresentam condições satisfatórias que permitam evitar a contaminação cruzada. A arquitetura destes ambientes deve ser revista, principalmente nas áreas de produção e empacotamento que não apresentam nenhum tipo de barreira física e revestimento de paredes e pisos que promovam a melhoria na qualidade microbiológica do ar.

O amostrador de impactação utilizado promoveu rapidez e proporcionou a expressão dos resultados em medidas confiáveis, por ser um equipamento que permite calibração em seu sistema de aspiração de ar. 


\section{REFERÊNCIAS BIBLIOGRÁFICAS}

ACUFF, G.R. Media, reagents, and stains. In: VANDERZANT, C.; SPLITTSTOESSER, D.F.(Ed.). Compendium of methods for the microbiological examination of foods. 3.ed. Washington: Edwards Brothers, 1992. chap.62, p.1093-1208.

\section{ANGULO-ROMERO, J.; INFANTE-GARCÍA-PANTALEÓN, $\quad$ F.; DOMÍNGUEZ-VILCHES, E.; MEDIAVILLA-MOLINA, A.; CARIDAD- OCERÍN, J.M. Pathogenic and antigenic fungi in school dust of the south of Spain. In: MUILENBERG, M.; BURGE, H. (Ed.). Aerobiology. Tokyo: Lewis Publishers, 1996. chap.5, p.49-66.}

BARNETT, H.L.; HUNTER, B.H. Illustrated genera of imperfect fungi. 3.ed. Minneapolis: Burgess Publishing Company, 1972. 241p.

BRASIL. Ministério da Saúde. Agência Nacional de Vigilância Sanitária. Portaria nº3.523/GM de 28 de agosto de 1998. Diário Oficial, 31 ago. 1998. Seção 1, p. 41- 42. Dispõe sobre orientação de medidas para controle do ar de interiores em ambientes climatizados. http://www.anvisa.gov.com.br. 
BRASIL. Ministério da Saúde. Agência Nacional de Vigilância Sanitária. Resolução ñ176 de 24 de outubro de 2000. Diário Oficial, 25 out. 2000. Dispõe-se sobre normas de controle da qualidade do ar de interiores em ambientes climatizados. http://www.anvisa.gov.com.br.

BRICKUS, L.S.R.; AQUINO NETO, F.R. de. A qualidade do ar de interiores e a química. Química Nova, v.22, n.1, p.1-10, 1999.

BUTTNER, M.P.; STETZENBACH, L.D. Monitoring airborne fungal spores in an experimental indoor environmental to evaluate sampling methods and the effects of human activity on air sampling. Applied and Environmental Microbiology, v.59, n.1, p.219-226, 1993.

EZEONU I.M.; PRICE, D.L.; SIMMONS, R.B.; CROW, S.A.; AHEARN, D.G. Fungal production of volatiles during growth on fiberglass. Applied and Environmental Microbiology, v.60, n.11, p.4172-4173, nov.1994.

FOOD and drug administration: bacteriological analytical manual. 8.ed. Gaithersburg: AOAC International, 1998. 1.01-28.09p.

FELDMAN, K. Sampling for airborne contaminants. Biocycle, v.36, n.8, p.84-86, Aug.1995.

FLANNIGAN, B.; MILLER, J.D. Health implications of fungi in indoor environments - an overview. In: SAMSON, R.A.; FLANNIGAN, B.; FLANNIGAN, M.E.; VERHOEFF, A.P.; ADAN, O.C.G.; HOEKSTRA, E.A.(Ed). Health implications of fungi in indoor environments. Tokyo: Elsevier, 1994. chap.1, p.3-38. (Air Quality Monographs, 2) 
KING, AD.; HOCKING, A.D.; PITT, J.I. Dichloran-Rose Bengal Medium for enumeration and isolation of molds from foods. Applied and Environmental Microbiology, v.37, n.5, p.959-964, May 1979.

KULCSAR NETO, F.; SIQUEIRA, L.F. de G. Padrões referenciais para análise de resultados de qualidade microbiológica em interiores visando a saúde pública no Brasil. Revista Brasindoor, v.2, n.10, p.4-20, jul./ago./set. 1998.

KURATA, $\mathrm{H}$. Mycological monitoring for sanitary evaluation in the japanese food industry. In: SAMSON, R.A.; FLANNIGAN, B.; FLANNIGAN, M.E.; VERHOEFF, A.P.; ADAN, O.C.G.; HOEKSTRA, E.A.(Ed.). Health implications of fungi in indoor environments. Tokyo: Elsevier, 1994. chap.2, p.31-37: Current methodology on isolation and detection of molds. (Air Quality Monographs, 2)

LACAZ, C. da S. O grande mundo dos fungos. São Paulo: Polígono AS, 1970. 255p.

LACAZ, C. da S; PORTO, E.; VACCARI, E.M.H.; MELO, N. T. Guia para identificação: fungos, actinomicetos, algas de interesse médico. São Paulo: Sarvier, 1998. 445p.

LIGUGNANA, R.; FUNG, D.Y.C. Training of food and dairy staff for microbiological air and surface hygiene. Dairy, Food and Environmental Sanitation, v.10, n.3, p.130-135, Mar.1990. 
MACNEIL, L.; KAURI, T.; ROBERTSON, W. Molecular techniques and their potential application in monitoring the microbiological quality of indoor air. Canadian Journal of Microbiology, v.41, p.657-665, 1995.

MERCK. Air MAS-100: microbiological air sample-operator's manual. Darmstadt, s.d. 47p.

NOGUEIRA, M.C.S. Curso de estatística experimental aplicada à experimentação agronômica. Piracicaba: ESALQ/USP, 1991. 236p.

PADRÃO referencial brasileiro microbiológico. Revista Brasindoor, v.2, n.10, p.21, jul./ago./set./1998.

PELCZAR, M.; REID, R.; CHAN, E.C.S. Microbiologia. São Paulo: McGraw-Hill, 1981. 1072p.

PITT, J.I; HOCKING, A D. Fungi and food spoilage. 2.ed. London: Blackie Academic \& Professional, 1997. 593p.

SVEUM, W.H.; MOBERG, L.J.; RUDE, R.A.; FRANK, J.F. Microbiological monitoring of the food processing environmental. In: VANDERZANT, C.; SPLITTSTOESSER, D.F.(Ed.). Compendium of methods for the microbiological examination of foods. 3.ed. Washington: Edwards Brothers, 1992. chap.3, p.51-74. 
TOURNAS, V.; STACK, M.E.; MISLIVEC, P.B.; KOCH, H.A.; BANDLER, R. Yeasts, molds and mycotoxins. In: Food and drug administration: bacteriological analytical manual. 8.ed. Gaithersburg: AOAC International, 1998. chap.18, p.18.01-18.09.

VANDERZANT, C.; SPLITTSTOESSER, D.F. Compendium of methods for the microbiological examination of foods. 3.ed. Washington: Edwards Brothers, 1992. 1219p.

WORLD HEALTH ORGANIZATION. Indoor air quality: biological contaminants: Rautavaara: WHO Regional Publications, 1988. 67p. (European Series, 31) 
APÊNDICES 
APÊNDICE 1

\begin{tabular}{|c|c|c|c|c|c|c|c|c|c|c|c|c|c|c|c|}
\hline R & $P r$ & $\underline{R}$ & $P r$ & $r$ & $\mathrm{Pr}$ & $r$ & $\mathrm{Pr}$ & & $\mathrm{Pr}$ & $r$ & $\mathrm{Pr}$ & $\mathrm{R}$ & $\mathrm{Pr}$ & $r$ & $\operatorname{Pr}$ \\
\hline 1 & 1 & 51 & 54 & 101 & 116 & 151 & 189 & 201 & 279 & 251 & 394 & 301 & 557 & 351 & 836 \\
\hline 2 & 2 & 52 & 56 & 102 & 118 & 152 & 191 & 202 & 281 & 252 & 397 & 302 & 561 & 352 & 844 \\
\hline 3 & 3 & 53 & 57 & 103 & 119 & 153 & 193 & 203 & 283 & 253 & 400 & 303 & 565 & 353 & 853 \\
\hline 4 & 4 & 54 & 58 & 104 & 120 & 154 & 194 & 204 & 285 & 254 & 402 & 304 & 569 & 354 & 861 \\
\hline 5 & 5 & 55 & 59 & 105 & 122 & 155 & 196 & 205 & 287 & 255 & 405 & 305 & 573 & 355 & 870 \\
\hline 6 & 6 & 56 & 60 & 106 & 123 & 156 & 197 & 206 & 289 & 256 & 408 & 306 & 578 & 356 & 879 \\
\hline 7 & 7 & 57 & 61 & 107 & 124 & 157 & 199 & 207 & 291 & 257 & 411 & 307 & 582 & 357 & 888 \\
\hline 8 & 8 & 58 & 63 & 108 & 126 & 158 & 201 & 208 & 293 & 258 & 413 & 308 & 586 & 358 & 897 \\
\hline 9 & 9 & 59 & 64 & 109 & 127 & 159 & 202 & 209 & 295 & 259 & 416 & 309 & 591 & 359 & 907 \\
\hline 10 & 10 & 60 & 65 & 110 & 128 & 160 & 204 & 210 & 297 & 260 & 419 & 310 & 595 & 360 & 917 \\
\hline 11 & 11 & 61 & 66 & 111 & 130 & 161 & 206 & 211 & 299 & 261 & 422 & 311 & 599 & 361 & 927 \\
\hline 12 & 12 & 62 & 67 & 112 & 131 & 162 & 207 & 212 & 301 & 262 & 425 & 312 & 604 & 362 & 937 \\
\hline 13 & 13 & 63 & 68 & 113 & 133 & 163 & 209 & 213 & 304 & 263 & 428 & 313 & 608 & 363 & 947 \\
\hline 14 & 14 & 64 & 70 & 114 & 134 & 164 & 211 & 214 & 306 & 264 & 431 & 314 & 613 & 364 & 958 \\
\hline 15 & 15 & 65 & 71 & 115 & 135 & 165 & 212 & 215 & 308 & 265 & 433 & 315 & 618 & 365 & 969 \\
\hline 16 & 16 & 66 & 72 & 116 & 137 & 166 & 214 & 216 & 310 & 266 & 436 & 316 & 622 & 366 & 981 \\
\hline 17 & 17 & 67 & 73 & 117 & 138 & 167 & 216 & 217 & 312 & 267 & 439 & 317 & 627 & 367 & 992 \\
\hline 18 & 18 & 68 & 74 & 118 & 140 & 168 & 218 & 218 & 314 & 268 & 442 & 318 & 636 & 368 & 1005 \\
\hline 19 & 19 & 69 & 76 & 119 & 141 & 169 & 219 & 219 & 317 & 269 & 445 & 319 & 637 & 369 & 1017 \\
\hline 20 & 20 & 70 & 77 & 120 & 142 & 170 & 221 & 220 & 319 & 270 & 449 & 320 & 642 & 370 & 1030 \\
\hline 21 & 22 & 71 & 78 & 121 & 144 & 171 & 223 & 221 & 321 & 271 & 452 & 321 & 647 & 371 & 1043 \\
\hline 22 & 23 & 72 & 79 & 122 & 145 & 172 & 224 & 222 & 323 & 272 & 455 & 322 & 652 & 372 & 1057 \\
\hline 23 & 24 & 73 & 80 & 123 & 147 & 173 & 226 & 223 & 325 & 273 & 458 & 323 & 657 & 373 & 1071 \\
\hline 24 & 25 & 74 & 82 & 124 & 148 & 174 & 228 & 224 & 328 & 274 & 461 & 324 & 662 & 374 & 1086 \\
\hline 25 & 26 & 75 & 83 & 125 & 150 & 175 & 230 & 225 & 330 & 275 & 464 & 325 & 667 & 375 & 1102 \\
\hline 26 & 27 & 76 & 84 & 126 & 151 & 176 & 232 & 226 & 332 & 276 & 467 & 326 & 673 & 376 & 1118 \\
\hline 27 & 28 & 77 & 85 & 127 & 153 & 177 & 233 & 227 & 335 & 277 & 471 & 327 & 678 & 377 & 1134 \\
\hline 28 & 29 & 78 & 87 & 128 & 154 & 178 & 235 & 228 & 337 & 278 & 474 & 328 & 684 & 378 & 1152 \\
\hline 29 & 30 & 79 & 88 & 129 & 156 & 179 & 237 & 229 & 339 & 279 & 477 & 329 & 689 & 379 & 1170 \\
\hline 30 & 31 & 80 & 89 & 130 & 157 & 180 & 239 & 230 & 342 & 280 & 480 & 330 & 695 & 380 & 1189 \\
\hline 31 & 32 & 81 & 90 & 131 & 158 & 181 & 241 & 231 & 344 & 281 & 484 & 331 & 701 & 381 & 1209 \\
\hline 32 & 33 & 82 & 92 & 132 & 160 & 182 & 242 & 232 & 346 & 282 & 487 & 332 & 706 & 382 & 1230 \\
\hline 33 & 34 & 83 & 93 & 133 & 161 & 183 & 244 & 233 & 349 & 283 & 491 & 33 & 712 & 383 & 1252 \\
\hline 34 & 35 & 84 & 94 & 134 & 163 & 184 & 246 & 234 & 351 & 284 & 494 & 334 & 718 & 384 & 1276 \\
\hline 35 & 37 & 85 & 95 & 135 & 164 & 185 & 248 & 235 & 353 & 285 & 497 & 335 & 724 & 385 & 1301 \\
\hline 36 & 38 & 86 & 97 & 136 & 166 & 186 & 250 & 236 & 356 & 286 & 501 & 336 & 730 & 386 & 1327 \\
\hline 37 & 39 & 87 & 98 & 137 & 167 & 187 & 252 & 237 & 358 & 287 & 504 & 337 & 737 & 387 & 1356 \\
\hline 38 & 40 & 88 & 99 & 138 & 169 & 188 & 254 & 238 & 361 & 288 & 508 & 338 & 743 & 388 & 1387 \\
\hline 39 & 41 & 89 & 101 & 139 & 171 & 189 & 255 & 239 & 363 & 289 & 511 & 339 & 749 & 389 & 1420 \\
\hline 40 & 42 & 90 & 102 & 140 & 172 & 190 & 257 & 240 & 366 & 290 & 515 & 340 & 756 & 390 & 1456 \\
\hline 41 & 43 & 91 & 103 & 141 & 174 & 191 & 259 & 241 & 368 & 291 & 519 & 341 & 763 & 391 & 1496 \\
\hline
\end{tabular}

Quadro 19 - Correção estatística "Feller".

$r$ = Número de unidades formadoras de colônias em 90 mm Petridish.

$\mathrm{Pr}=$ Probabilidade estatística total. 


\begin{tabular}{|l|l|l|l|l|l|l|l|l|l|l|l|l|l|l|l|}
\hline 42 & 44 & 92 & 104 & 142 & 175 & 192 & 261 & 242 & 371 & 292 & 522 & 342 & 769 & 392 & 1541 \\
\hline 43 & 45 & 93 & 106 & 143 & 177 & 193 & 263 & 243 & 373 & 293 & 526 & 343 & 776 & 393 & 1591 \\
\hline 44 & 47 & 94 & 107 & 144 & 178 & 194 & 265 & 244 & 376 & 294 & 530 & 344 & 783 & 394 & 1648 \\
\hline 45 & 48 & 95 & 108 & 145 & 180 & 195 & 267 & 245 & 378 & 295 & 534 & 345 & 791 & 395 & 1715 \\
\hline 46 & 49 & 96 & 110 & 146 & 181 & 196 & 269 & 246 & 381 & 296 & 537 & 346 & 798 & 396 & 1795 \\
\hline 47 & 50 & 97 & 111 & 147 & 183 & 197 & 271 & 247 & 384 & 297 & 541 & 347 & 805 & 397 & 1895 \\
\hline 48 & 51 & 98 & 112 & 148 & 185 & 198 & 273 & 248 & 386 & 298 & 545 & 348 & 813 & 398 & 2028 \\
\hline 49 & 52 & 99 & 114 & 149 & 149 & 199 & 275 & 249 & 389 & 299 & 549 & 349 & 820 & 399 & 2228 \\
\hline 50 & 53 & 100 & 115 & 150 & 188 & 200 & 277 & 250 & 391 & 300 & 553 & 350 & 828 & 400 & 2628 \\
\hline
\end{tabular}

Quadro 19 - Correção estatística "Feller".

$r=$ Número de unidades formadoras de colônias em 90 mm Petridish.

$\operatorname{Pr}=$ Probabilidade estatística total. 


\section{APÊNDICE 2}

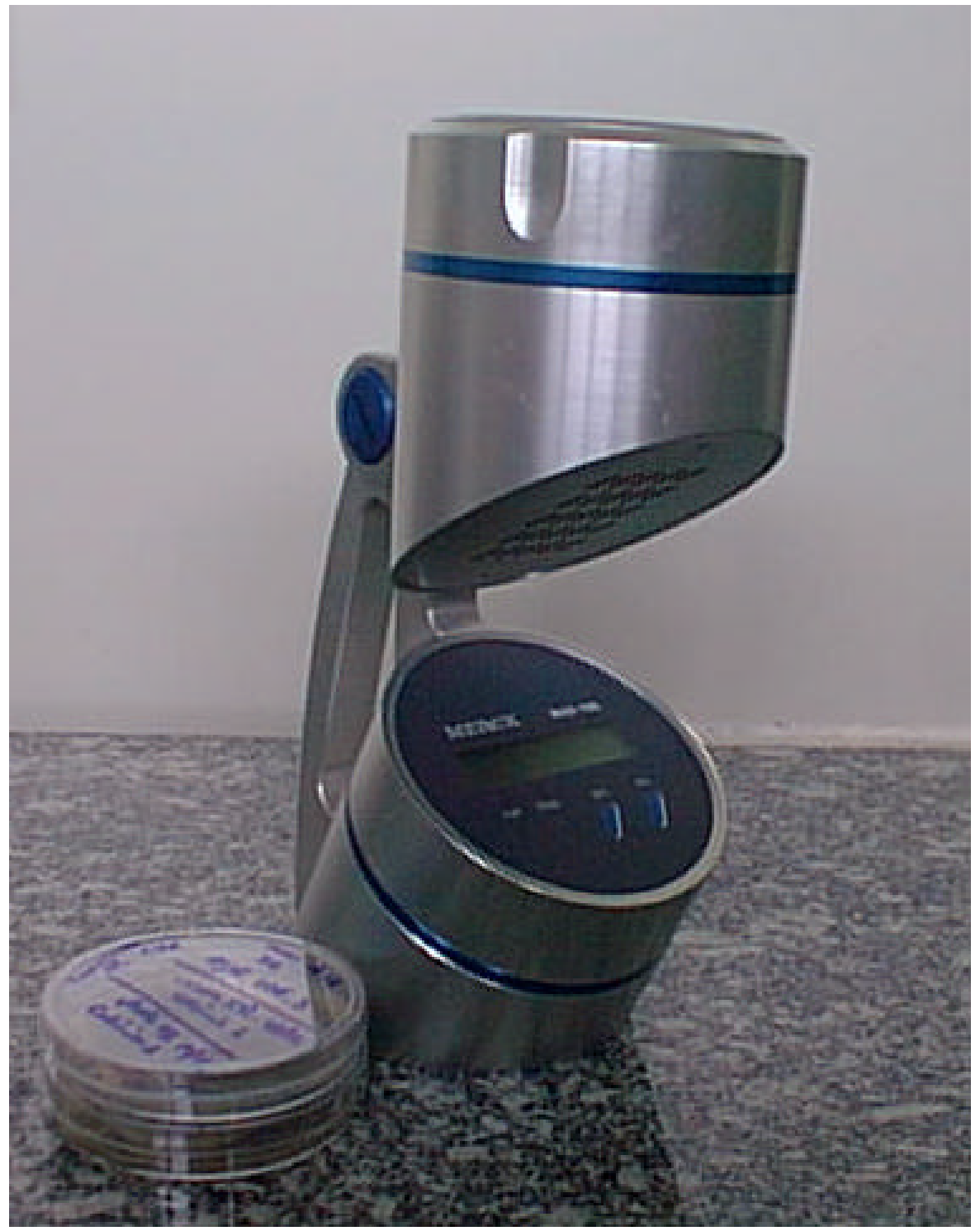

Figura 1 - Amostrador microbiológico de ar da marca MERCK denominado MAS-100. 